\title{
Determination of an Optimal Oil Jet Nozzle Layout for Helical Gear Lubrication: Mathematical Modeling, Numerical Simulation, and Experimental Validation
}

\author{
Yu Dai $\mathbb{D}^{1},{ }^{1}$ Jifu Jia, ${ }^{1}$ Bin Ouyang, ${ }^{2}$ and Jianeng Bian ${ }^{1}$ \\ ${ }^{1}$ College of Mechanical and Electrical Engineering, Central South University, Changsha 410083, China \\ ${ }^{2}$ AECC Hunan Aviation Powerplant Research Institute, Zhuzhou 412000, China \\ Correspondence should be addressed to Yu Dai; 210143@csu.edu.cn
}

Received 25 December 2019; Revised 10 February 2020; Accepted 24 February 2020; Published 12 May 2020

Academic Editor: Honglei Xu

Copyright (C) 2020 Yu Dai et al. This is an open access article distributed under the Creative Commons Attribution License, which permits unrestricted use, distribution, and reproduction in any medium, provided the original work is properly cited.

\begin{abstract}
To provide a basic guidance for the selection of nozzle layout, a mathematical model of the impingement depth for helical gears under oil jet lubrication is established. Furthermore, computational fluid dynamics (CFD) methods are adopted to validate the effectiveness and accuracy of the derived impingement model. Firstly, the distribution characteristics of the oil volume fraction and oil-gas pressure in meshing area were obtained in flow field simulation. Meanwhile, the influence of spray angle, jet velocity, and gear ratio on lubrication effect was obtained. Then, the transient temperature field of the tooth surface was simulated by the method of thermal-fluid coupling analysis, and the lowest temperature distribution and the corresponding oil jet velocity were determined. Finally, experiments on the temperature characteristics measured by an infrared thermal imager of helical gears with different nozzle parameters were carried out in a gear test rig. The simulation results of transient temperature field are in good agreement with those obtained by experiments, and it indicates that the thermal-fluid coupling analysis method is correct and feasible to predict the temperature field of the helical gear pair under oil injection jet lubrication.
\end{abstract}

\section{Introduction}

The main reducer is the core component in helicopter transmission system. Under the condition of high speed and heavy load, a high temperature rise easily appears on the tooth surface of helical gears and seriously affects the transmission performance of helical gears and the main reducer. Helical gears inside main reducer are commonly lubricated and cooled with oil jet lubrication. The layout parameters of nozzle have a significant impact on the lubrication and cooling performance. Therefore, the effects of the layout parameters of nozzle on the flow field and temperature field characteristics of helical gears are of great significance.

McCain et al. studied the out-of-mesh oil jet lubrication phenomenon and defined the oil jet impingement depth for meshed gears [1]. Akin and Townsend conducted a series of studies on the oil jet lubrication of spur and helical gears under the into-mesh, out-of-mesh, and radial direction conditions. Their study found that the oil jet lubrication effect was not only related to the oil jet parameters and gear ratio parameters but also influenced by the oil jetting position and angle [2-5]. Wang et al. established the CFD model of oil jet lubrication for spur gear, and the effects of spray angle and distance on lubrication performance under into-mesh oil jet lubrication and out-of-mesh conditions were compared. The lubrication mode depends on the ratio of gear linear speed to oil jet velocity, which is verified by corresponding experiments [6,7]. Li et al. established the numerical model of spraying oil and oil film spreading and obtained the relationship between spray lubrication parameters and spreading characteristics of oil film. The film thickness in the elasto-hydrodynamic lubrication and its lubricating state of the meshing points are also analyzed [8]. Wang et al. employed a multiphase flow model to calculate the flow regimes of oil jet under the effect of spin flow [9]. Dai et al. also adopted a two-phase mixture flow model to simulate the oil jet lubrication on the surface of a pair of spur 
gears. The oil volume and oil pressure distribution characteristics in the meshing area under different nozzle position layouts were obtained; therefore, an optimal nozzle layout was recommended [10, 11]. High-speed infrared testers and infrared sensors have been adopted to measure the instantaneous tooth temperature to study the influence of the speed, load, and jet location on the lubrication performance $[12,13]$. Kahraman et al. conducted a set of experiments to quantify the impact of lubrication methods on spur gears, the power losses, and contact fatigue lives [14]. Massini et al. exploited a novel rotating test rig to analyze oil jet lubrication through high-speed visualizations, and an oil jet impinging radially on a single spur gear was generated by a spray bar, assessing which parameters affect the oil jet behavior [15]. Tommaso et al. used the volume of fluid (VOF) method to carry out a comprehensive numerical study about a single oil jet impinging radially on a single spur gear tooth. They developed an adaptive mesh approach to allow an automatic mesh refinement and/or coarsening at the air-oil interface. Their study found the effects of the oil injection angle on resistant torque and the lubrication performances [16]. Satya et al. simplified the fluid-mechanics model and decomposed the gear wind resistance loss into two parts: pressure and viscous. The total windage power loss is defined, and its predictions are compared to published gear pair windage experiments and empirical formulae to assess their accuracy [17]. Ouyang et al. introduced a novel model based on tribodynamic theory to investigate the lubricating and dynamic performances of high-speed spur gear [18]. Gan et al. proposed a numerical method integrating the mixed elasto-hydrodynamic lubrication model with a finite element method based on thermal analysis to analyze the bulk and flash temperature behaviors [19]. Wang et al. built equations for the contact path of the face gear loaded tooth contact analysis (LTCA) on the basis of the load equivalent error of alignment (LEEA), and the load distribution among the teeth was calculated [20]. Liu et al. established a comprehensive mechanical efficiency model based on the thermal elasto-hydrodynamic lubrication (TEHL) for a helical gear pair [21].

However, few open published literatures have concerned the influence of different spray angles, oil jet velocity, and gear ratio on lubrication performance. Aiming to provide theoretical guidance for the layout of helical gear nozzles under the condition of oil jet lubrication, this paper accomplished the flow field and temperature field simulations and carried out a set of corresponding experiments to validate the thermal-fluid coupling analysis method is correct and feasible.

\section{Mathematical Model}

In the rotating process of a helical gear pair under jet lubrication condition, the initial time is set as $t_{0}$, and the position parameters of the driving and driven gears (the pinion and gear) at this moment are expressed by the geometrical relationship of the helical gear pair end face. After a period of time, the relationship between the position of the driving and driven gears and oil stream at time $t$ is established. Since the jet flow flighting time is equal to the rotation time of the helical gear pair from the initial time $t_{0}$ to the final time $t$, the impingement points on the meshing surfaces of the driving and driven gears can be determined. Thus, the mathematical model of impingement depth is deduced.

2.1. Definition of Nozzle Layout Parameters. The layout parameters of the nozzle under the oil jet lubrication condition mainly include offset distance $S$, oil injection angle $\beta$, deviation distance $L$, and oil jet height $H$. The definitions of each parameter are shown in Figure 1.

The offset distance $S$ is defined as the straight-line distance between the jetting point and the common tangent of the indexing circle of the pinion and gear; the oil injection angle $\beta$ describes the included angle between the oil jet flow and the common tangent of the indexing circle of the pinion and gear; the deviation distance $L$ is the straight-line distance between the nozzle and the common tangent of the indexing circle between the pinion and gear. The oil jet height $H$ denotes the linear distance between the nozzle and the center line of the pinion and gear. The parameters above are positive to the pinion and negative to the gear.

\subsection{The Range of Offset Distance and Oil Injection Angle.}

$$
\begin{aligned}
0 & \leq S \leq S_{0}, \\
S_{0} & =\frac{a_{g r} m_{g}-a_{p r}}{m_{g}+1}+\frac{a_{g r}^{2}-a_{p r}^{2}}{2 r_{r}\left(m_{g}+1\right)},
\end{aligned}
$$

where $a_{g r}$ and $a_{p r}$ represent the corrected tooth tip height for large and small gears, respectively; $m_{g}$ is the gear ratio; and $r_{r}$ is the modified pitch circle radius of the pinion. If the pinion and gear are unmodified, equation (2) can be classified as

$$
S_{0}=\frac{a_{g} m_{g}-a_{p}}{m_{g}+1},
$$

where $a_{g}$ and $a_{p}$ are the standard tooth addendum of the pinion and gear, respectively.

$$
\begin{aligned}
& \beta_{\text {min }} \leq \beta \leq \beta_{\text {max }}, \\
& \left\{\begin{array}{l}
\beta_{\min }=\tan ^{-1}\left[\frac{\left(S-a_{g}\right)}{R_{i}}\right], \\
\beta_{\max }=\tan ^{-1}\left[\frac{\left(S+a_{p}\right)}{R_{i}}\right],
\end{array}\right.
\end{aligned}
$$

where $R_{i}$ is the normal offset, and

$$
R_{i}=\sqrt{R_{o}^{2}-R_{s}^{2}}
$$

where $R_{o}$ is the radius of addendum circle of the gear, and 


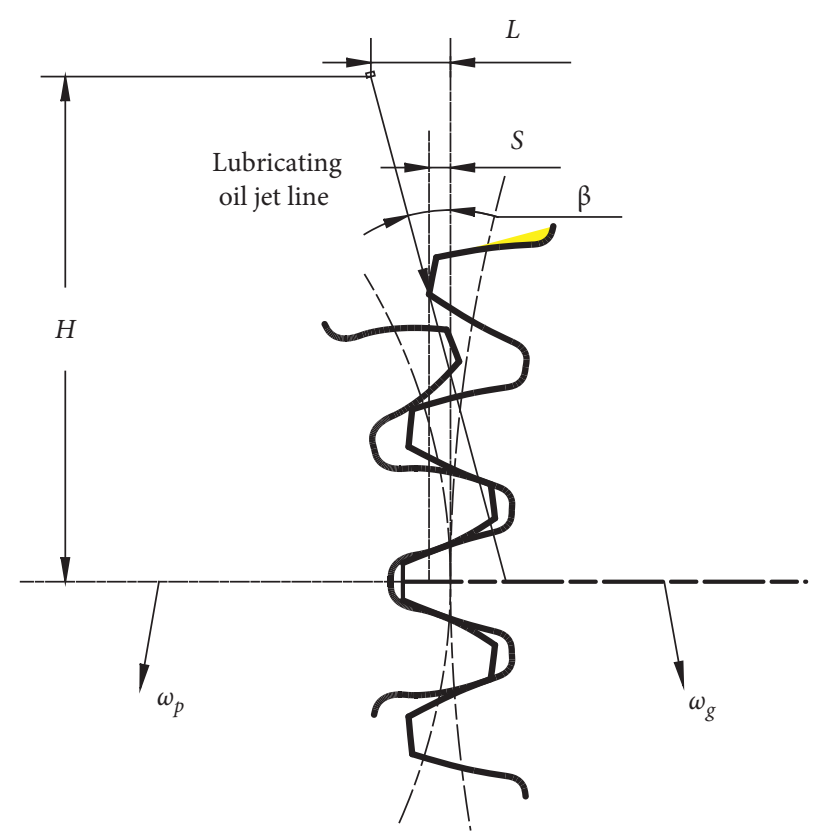

FIGURE 1: Layout parameters of gear nozzle.

$$
R_{o}=\frac{1}{2}\left(\frac{N_{g}}{\cos \psi}+2 h_{a}^{*}\right) m_{n}
$$

where $h_{a}^{*}$ is the tooth addendum coefficient, and $h_{a}^{*}=1$ here.

$$
R_{\mathrm{S}}=R+S,
$$

where $R$ is the pitch circle radius of the gear, and

$$
R=\frac{C N_{g}}{N_{g}+N_{p}} \text {. }
$$

If the oil stream line is inclined to the large gear, $\beta$ becomes negative and vice versa. The positive oil injection angle is generally adopted.

2.3. Calculation of Impingement Depth. In general, the jet velocity $V_{j}$ is given; then, the calculating process of impingement depth on the pinion is as follows.

At the initial time $t_{0}=0$, the positions of the oil jet flow line, the pinion, and gear are as shown in Figure 2.

From the geometric relationship of the helical gear pair, it can be known that

$$
r_{x}=r-S+x,
$$

where $r_{x}$ is the distance from the intersection point of jet line and gear center line to the pinion center and $r$ is the pitch radius of the pinion, and

$$
r=\frac{C N_{p}}{N_{g}+N_{p}}
$$

where $C$ is the standard center distance of gear and $N_{g}$ and $N_{p}$ are the number of teeth of the pinion and gear, respectively.

$x$ is the distance from its vertical foot to the intersection of the jet line and the center line, and

$$
x=R_{i} \cdot \tan \beta .
$$

According to the geometrical relation, $r_{a}$ is the vertical distance from the center of the pinion to the jet line:

$$
r_{a}=r_{x} \cos \beta .
$$

In Figure 2, $\theta_{p 1}$ and $\theta_{g 1}$ are, respectively, denote the angular position of the pinion and gear at the initial time $t=0$, and

$$
\begin{aligned}
& \theta_{p 1}=m_{g} \theta_{g 1}+\operatorname{inv} \phi_{t}-\beta, \\
& \theta_{g 1}=\cos ^{-1} \frac{R_{s}}{R_{o}}-\operatorname{inv} \phi_{o g}+\operatorname{inv} \phi,
\end{aligned}
$$

where inv $\phi$ and inv $\phi_{t}$ are, respectively, the function of the pressure angle of the pinion and gear, indicating the angle of expansion at the intersection of the reference circle and the involute of the pinion and gear, and

$$
\begin{aligned}
\text { inv } \phi & =\tan \phi-\phi, \\
\text { inv } \phi_{t} & =\tan \phi_{t}-\phi_{t},
\end{aligned}
$$

where $\phi$ and $\phi_{t}$ are, respectively, the pressure angles on the reference circle of the pinion and gear, and

$$
\phi=\phi_{t}=\tan ^{-1}\left(\frac{\tan \alpha_{n}}{\cos \psi}\right)=\cos ^{-1}\left(\frac{R_{b}}{R}\right)=\cos ^{-1}\left(\frac{r_{b}}{r}\right),
$$




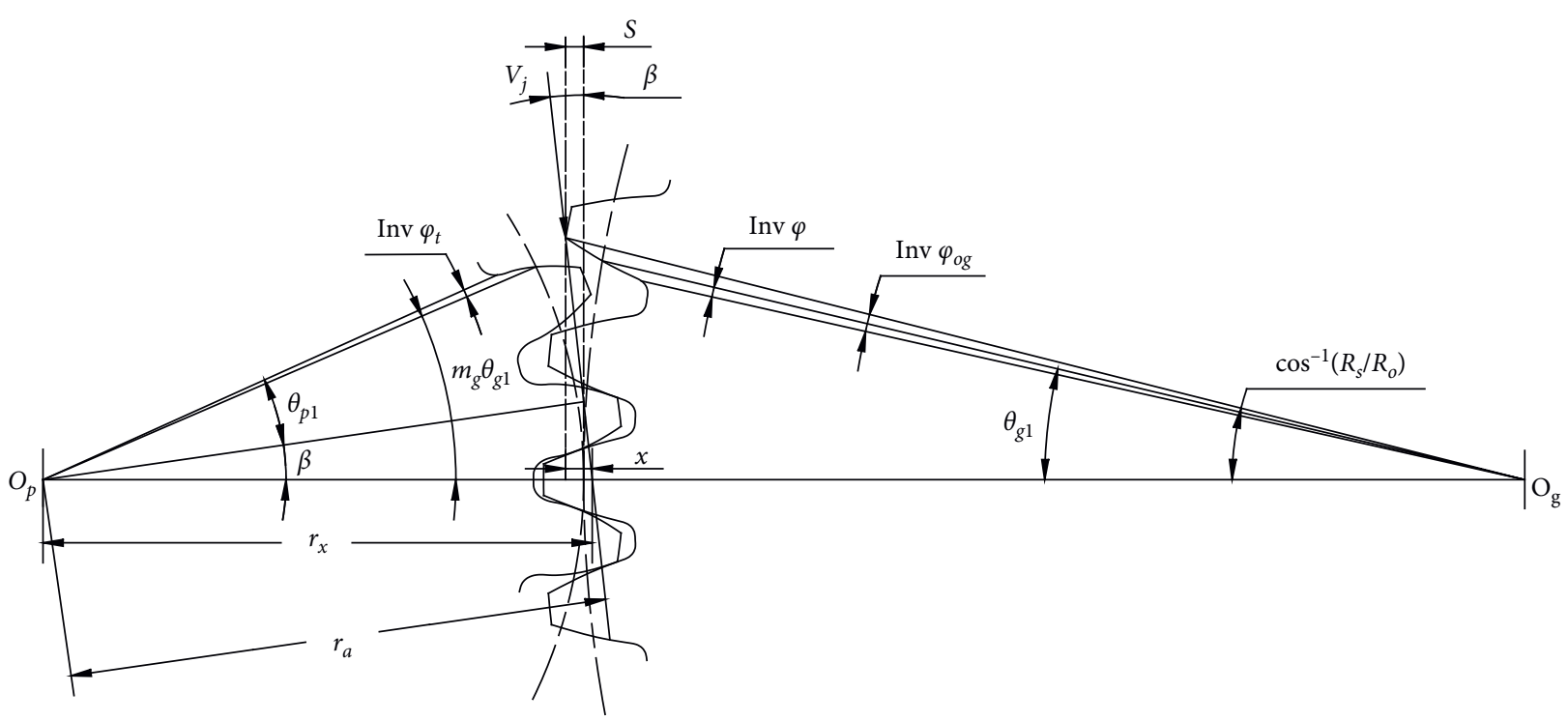

Figure 2: Diagram of impingement depth on the pinion $\left(t_{0}=0\right)$.

where $\alpha_{n}$ is the normal pressure angle of the helical gear, $\psi$ is the spiral angle of the helical gear, $R$ and $r$ are, respectively, the reference radii of the gears, and $R_{b}$ and $r_{b}$ are, respectively, the base circle radii of the gears; from equation (8),

$$
\begin{aligned}
R_{b} & =R \cos \phi, \\
r_{b} & =r \cos \phi_{t},
\end{aligned}
$$

where inv $\phi_{\text {og }}$ represents the angle of expansion at the intersection of the addendum circle and the involute of the gear, inv $\phi_{o g}=\tan \phi_{o g}-\phi_{o g}$, and $\phi_{o g}$ is the pressure angle on the addendum circle of the gear, and

$$
\phi_{o g}=\cos ^{-1}\left(\frac{R_{b}}{R_{0}}\right) \text {. }
$$

At the time $t_{1}=t$, the positions of the oil jet flow line, the pinion, and gear are as shown in Figure 3.

According to the geometric relationship of the helical gear pair, it can be known that

$$
\left(r_{o}-d_{p}\right)^{2}=L_{p}^{2}+r_{a}^{2}
$$

where $L_{p}$ is the impingement distance and $r_{o}$ is the outside radius of the pinion, and

$$
r_{0}=\frac{1}{2}\left(\frac{N_{p}}{\cos \psi}+2 h_{a}^{*}\right) m_{n}
$$

where $h_{a}^{*}$ is the tooth addendum coefficient, and $h_{a}^{*}=1$ here.

From time $t_{0}$ to $t_{1}$, the distance traveled of the oil flow is $\Delta h$, and $\theta_{p 2}$ is the position parameter at time $t_{1}$. According to the gear, rotation time is equal to the lubricating oil jet flow time; thus,

$$
\frac{\theta_{p 2}-\theta_{p 1}}{w_{p}}=\frac{\Delta h}{V_{j}},
$$

where $w_{p}$ is the angular velocity of the pinion.

$$
\theta_{p 2}=\tan ^{-1} \frac{L_{p}}{r_{a}}+\operatorname{inv} \phi_{p 2}
$$

where inv $\phi_{p 2}=\tan \phi_{p 2}-\phi_{p 2}$ and inv $\phi_{p 2}$ is the expansion angle at the point of impingement on the involute, and

$$
\phi_{p 2}=\cos ^{-1}\left(\frac{r_{b}}{r_{i}}\right) \text {, }
$$

where $r_{i}$ is the radius of the pinion at the impingement point.

$$
r_{i}=\left(L_{p}^{2}+r_{a}^{2}\right)^{1 / 2} .
$$

Obviously, $\theta_{p 2}$ is a function of $L_{p}$ and can be solved by iterative computing, so

$$
\Delta h=\frac{V_{j}\left(\theta_{p 2}-\theta_{p 1}\right)}{w_{p}} .
$$

According to Figures 2 and 3, the impingement distance $L_{p}$ is

$$
L_{p}=\frac{\left(R_{o}^{2}-R_{s}^{2}\right)^{1 / 2}}{\cos \beta}-\frac{V_{j}\left(\theta_{p 2}-\theta_{p 1}\right)}{w_{p}}-r_{x} \sin \beta .
$$

Combining equation (18),

$$
d_{p}=r_{o}-\sqrt{r_{a}^{2}+L_{p}^{2}} .
$$

Substituting equations (9), (11), (12), and (19) into equations (25) and (26), the mathematical model of the impingement depth on the pinion is obtained:

$$
d_{p}=\frac{N_{p} m_{n}}{2 \cos \psi}+m_{n}-\sqrt{\left(\left(r-S+R_{i} \cdot \tan \beta\right) \cdot \cos \beta\right)^{2}+L_{p}^{2}},
$$

where 


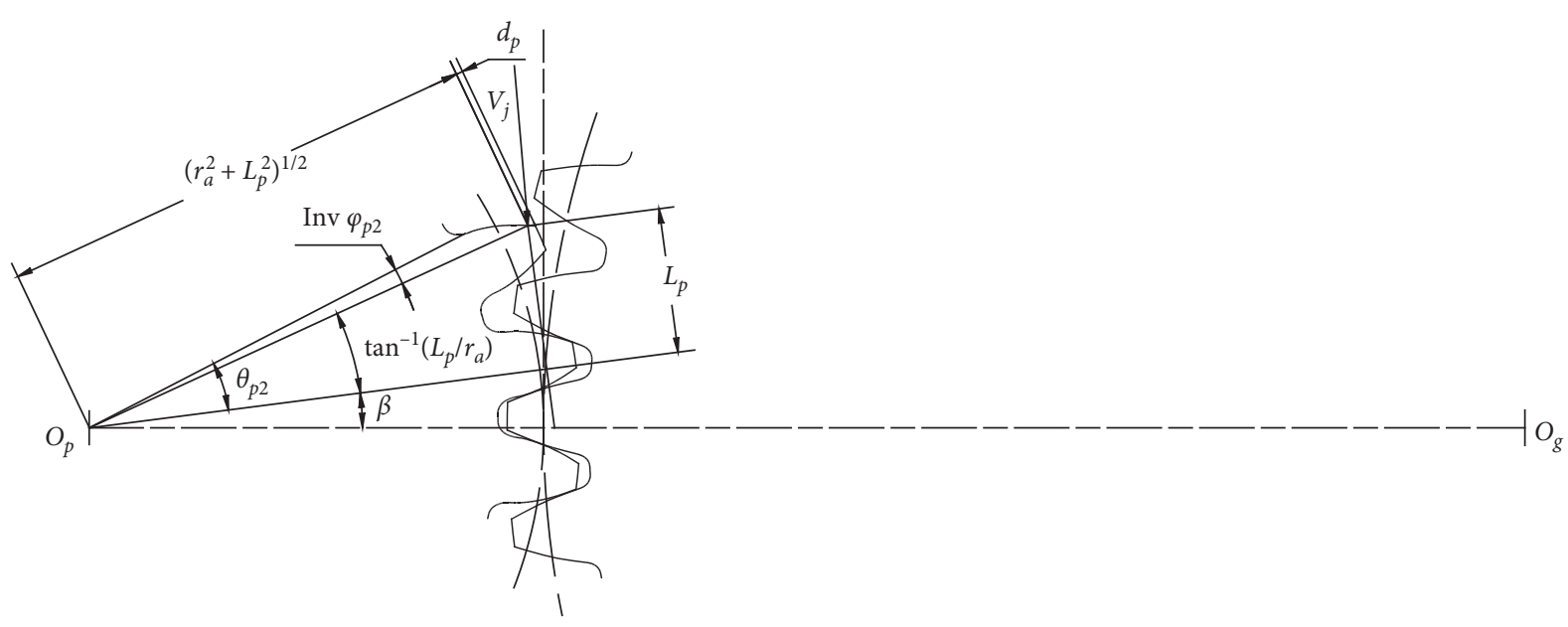

FIgURE 3: Diagram of impingement depth on the pinion $\left(t_{1}=t\right)$.

$L_{p}=\frac{\left(R_{o}^{2}-R_{s}^{2}\right)^{1 / 2}}{\cos \beta}-\frac{V_{j}\left(\theta_{p 2}-\theta_{p 1}\right)}{w_{p}}-\left(r-S+R_{i} \cdot \tan \beta\right) \cdot \sin \beta$.

\section{Flow Field Simulation and Optimization}

3.1. Influence of Different Injection Angles on Lubrication Effect. The geometry parameters of the helical gear pair are shown in Table 1.

The nozzle layout parameters including injection angles and offset distances are shown in Table 2, and the oil jet height $H$ is $60 \mathrm{~mm}$.

The main settings for numerical simulation in this paper are as follows: the pressure-based solver is used, and the time option is set to transient; the influence of gravity is taken into account; the multiphase flow model is set as the VOF model, the implicit body force option is activated, the RNG $k$-epsilon model is selected as the turbulence model, and the near wall is treated as standard wall functions; because of the injection of lubricating oil into the air, the primary phase is air, and the secondary phase is lubricating oil. The outlet velocity of the nozzle is the speed inlet, and the spray velocity and hydraulic diameter are $30 \mathrm{~m} / \mathrm{s}$ and $0.0014 \mathrm{~m}$, respectively. All walls use nonslip boundary conditions, that is, the wall speed is 0 . In the solution method, standard SIMPLE algorithm is used for pressure velocity coupling, the least squares cell-based method is used for gradient difference, PRESTO is used for pressure term, and second-order upwind is used for momentum term.

Dynamic grid technology is adopted to simulate the rotation of the helical gear pair, and the separation method is employed to appropriately increase the gear center distance. To set the dynamic grid area, first edit the user-defined function and import the prepared profile files into Fluent, as shown below. Dynamic mesh is then used, combining spring layer smoothing with remeshing; the dynamic grid region was selected as the interior solid, and the dynamic grid form was selected as rigid.
TABLE 1: Geometry parameters of the helical gear pair.

\begin{tabular}{lccc}
\hline Parameter & Pinion & & Gear \\
\hline Number of teeth & 22 & & 47 \\
Module & & $3.75 \mathrm{~mm}$ & \\
Spiral angle & & $11^{\circ}$ & \\
Pressure angle & & $20^{\circ}$ & \\
Speed of revolution & $3000 \mathrm{r} / \mathrm{min}$ & & $1404.3 \mathrm{r} / \mathrm{min}$ \\
Center distance & & $132 \mathrm{~mm}$ & \\
Tooth width & & $20 \mathrm{~mm}$ & \\
\hline
\end{tabular}

TABle 2: Nozzle layout parameters.

\begin{tabular}{lcc}
\hline Number & Injection angle, $\beta\left(^{\circ}\right)$ & Offset distance, $L(\mathrm{~mm})$ \\
\hline 1 & 0 & 0 \\
2 & 2.5 & 1.2539 \\
3 & 5 & 2.5127 \\
4 & 7.5 & 3.7811 \\
5 & 10 & 5.0641 \\
\hline
\end{tabular}

((pinion_rotation 2 point)

(time 0 1)

(omega_z -314.159265-314.159265))

((gear_rotation 2 point)

(time 0 1)

(omega_z 147.07831 147.07831))

In order to ensure the reliability of the simulation results, the grid independence test is carried out. A plane $y=0.1 \mathrm{~mm}$ is created near the meshing zone, the injection velocity is $30 \mathrm{~m} / \mathrm{s}$, and the spray angle is $5^{\circ}$; when the gear is running for $0.005 \mathrm{~s}$, the oil pressure in the plane along the tooth width direction is measured. Taking the number of grid elements as the only independent variable, Table 3 lists the number of grid cells in six cases. It can be seen from the simulation results that when the number of grids increases to case 4 , the oil pressure tends to be stable, as shown in Figure 4. As a result, the total number of grid elements in all the simulations below is controlled at about 850,000 . 
TABLE 3: Cases of grid elements.

\begin{tabular}{lc}
\hline Cases & Total grid elements \\
\hline 1 & 265,925 \\
2 & 425,458 \\
3 & 654,984 \\
4 & 849,759 \\
5 & $1,056,564$ \\
6 & $1,320,893$ \\
\hline
\end{tabular}

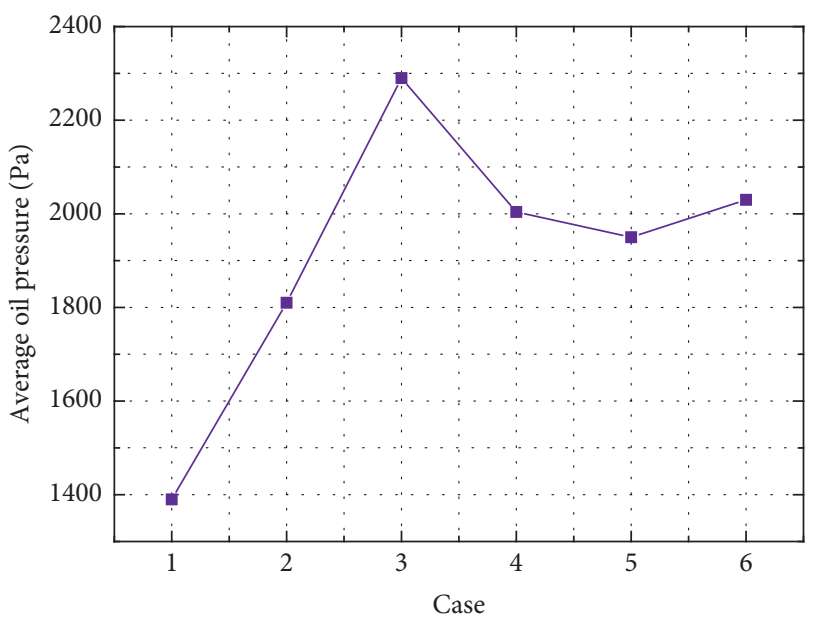

FIgURE 4: Average oil pressure under six cases.

We import the geometric model of the gearbox into the geometry modeling module of ANSYS to create the fluid domain and then generate mesh in the mesh module. The helical gear pair and fluid domain were divided into unstructured tetrahedral meshes to meet the needs of dynamic meshes, and local refinement was used to refine the meshes at the gear boundary and the nozzle, as shown in Figure 5. The minimum mesh size is $0.3 \mathrm{~mm}$, the maximum size is $16 \mathrm{~mm}$, the number of grids is about 850,000 , and the maximum skew is 0.83 .

The above established model is imported into the Fluent for flow field analysis. Oil jet velocity is set to $30 \mathrm{~m} / \mathrm{s}$, the driving wheel rotates clockwise, and the rotation speed is $3000 \mathrm{r} / \mathrm{min}$. The time step is $1 . e-005 \mathrm{~s}$, and the number of iteration steps is 500 steps.

In general, considerable amounts of heat are generated in the process of engagement and poor heat dissipation capability for the driving gear results in pitting, scuffing, and scoring failure on tooth surface. Therefore, this paper mainly concerns the distribution of lubricating oil on tooth surface of the pinion, and the simulation results of fluid field under different injection angles are shown in Figure 6.

As can be seen from Figure 6, the axial force causes the oil in the meshing zone to be squeezed to flow along one side in the tooth width direction, resulting in a large integral of the oil lubricant on the side tooth surface. From the distribution of the oil on tooth surface of the driving gear, it can be visually seen that the oil spot area and the oil volume fraction of the tooth surface are larger at the angle of $5^{\circ}$ and $7.5^{\circ}$ and more uniformly distributed in the tooth width direction. According to Figure 6, only the oil volume fraction with an injection angle of $5^{\circ}$ and $7.5^{\circ}$ is larger, but the best cannot be recognized.

Based on the theory proposed by Dowson et al. [22-24], the oil pressure on a plane near the meshing zone is regarded as a criterion for judging the gear lubrication performance. Therefore, a plane $y=0.1 \mathrm{~mm}$ is created near the meshing zone, and a scatter plot of the oil pressure distribution along the tooth width direction at time $0.005 \mathrm{~s}$ is plotted, as shown in Figure 7.

As can be seen from Figure 7, the peak of the oil pressure and the most densely part along the tooth width direction appear near $z=0.005 \mathrm{~mm}$, indicating that the oil gathers in the $z^{+}$direction under the tooth surface pressing, resulting in a higher pressure in this side. It can be also seen that the oil pressure is the largest when the injection angle is $5^{\circ}$ and is widely distributed in the tooth width direction so that a better lubrication and cooling effect can be determined.

Figure 8 shows the oil pressure on the plane $y=0.1 \mathrm{~mm}$ near the meshing zone versus different injection angles. It can be seen that the maximum positive pressure, the average positive pressure, the maximum negative pressure, and the average negative pressure are all the highest when the injection angle is $5^{\circ}$. They are $21404.6 \mathrm{~Pa}, 2003.96 \mathrm{~Pa}$, $-28336.9 \mathrm{~Pa}$, and $-547.83 \mathrm{~Pa}$, respectively. So, the lubrication effect is best when the injection angle of the nozzle is $5^{\circ}$.

\subsection{Influence of Different Oil Jet Velocities on Lubrication} Effect. With the same gear geometry and operating conditions, the lubrication effect is closely related to the ratio of oil jet velocity to gear speed. In this paper, the gear parameters and the speed of the pinion remain unchanged. The influence of the oil jet velocity on the lubrication effect of the helical gear is investigated.

With the conclusions in the previous section, the injection angle of $5^{\circ}$ was selected, and oil jet velocity was set to $20,25,30,35$, and $40 \mathrm{~m} / \mathrm{s}$, respectively. The rotation speed of the driving gear is $3000 \mathrm{r} / \mathrm{min}$, and the oil distribution is shown in Figure 9. In order to conveniently compare the oil distribution of oil on the tooth surface, the range of oil volume fraction is from 0 to 0.25 .

As shown in Figure 9, when the oil jet velocity is $30 \mathrm{~m} / \mathrm{s}$, the oil spot area on the tooth surface and the oil volume fraction (the red area in the figure) both reach the maximum value. When the oil jet velocity is greater than $30 \mathrm{~m} / \mathrm{s}$, as the oil jet velocity increases, the oil spot area of the tooth surface increases, but the oil volume fraction decreases. This is because the splash phenomenon of the oil at the impingement point becomes more and more serious, resulting in the decrease of the oil flowing into the meshing zone.

In order to further determine the optimal value, an oil pressure distribution scatter plot (shown in Figure 10) and an oil pressure against the oil jet velocity (shown in Figure 11) on the plane $y=0.1 \mathrm{~mm}$ near the meshing zone are illustrated. As seen in Figure 10, the peak value of oil pressure and the density of its distribution along the tooth width are the largest when the injection speed is $30 \mathrm{~m} / \mathrm{s}$. It can be seen from Figure 11 that the maximum value and the 


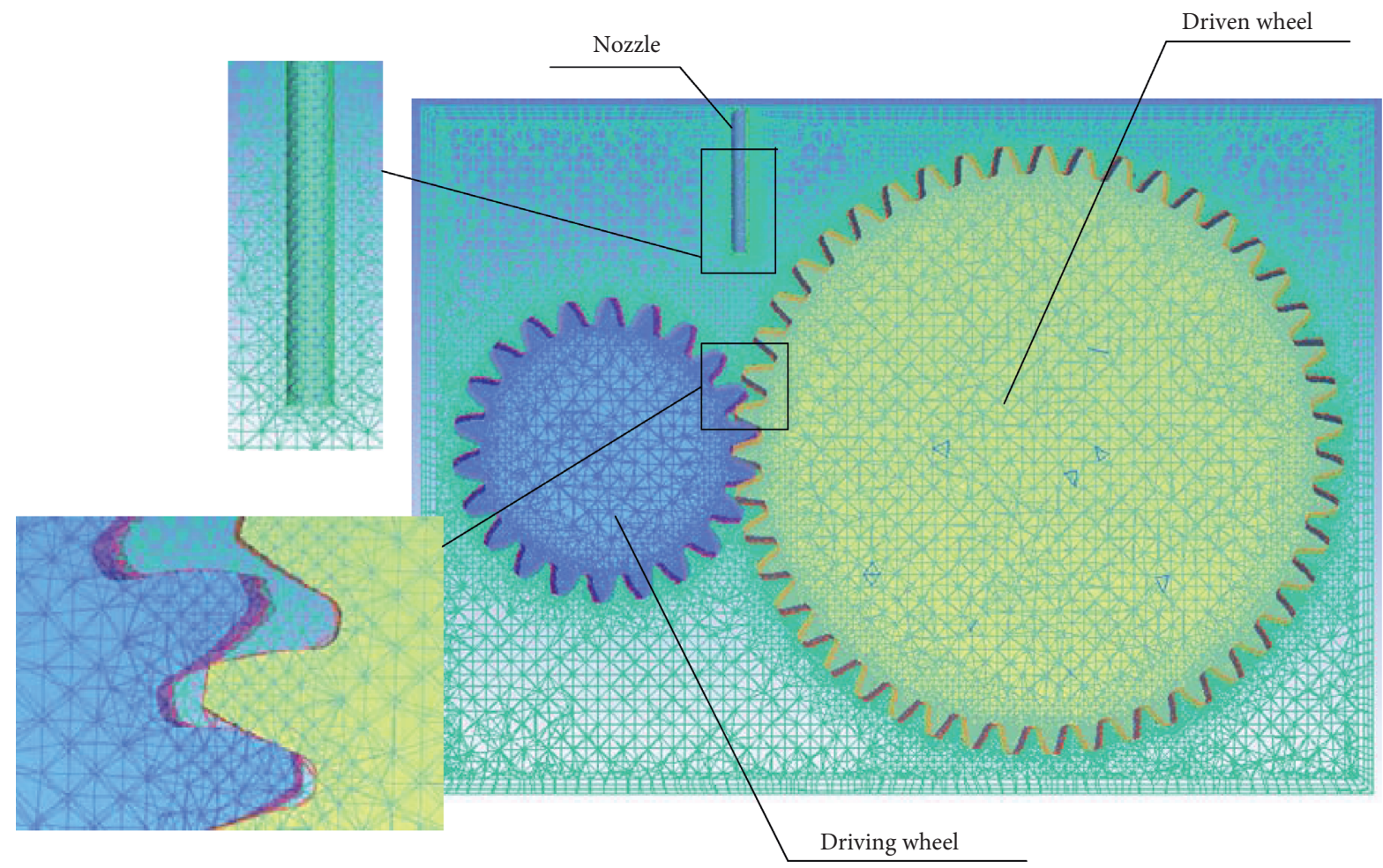

Figure 5: Mesh model of gear pair and box.

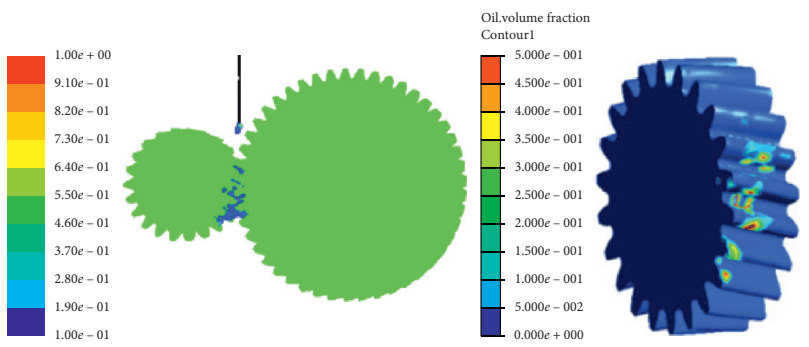

(a)

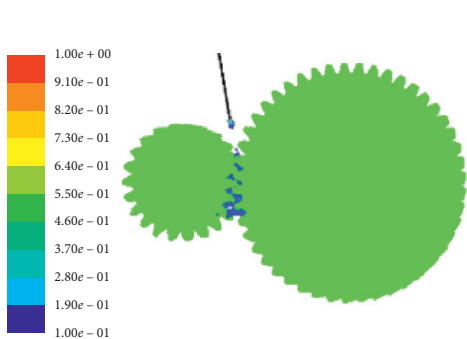

(c)

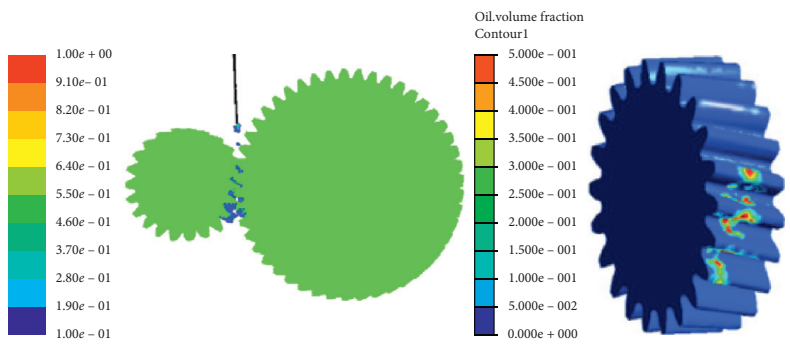

(b)

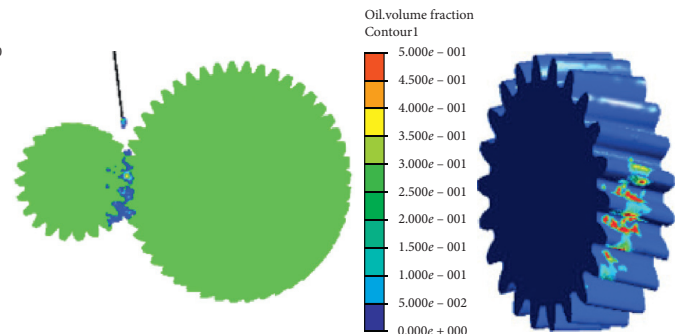

(d)

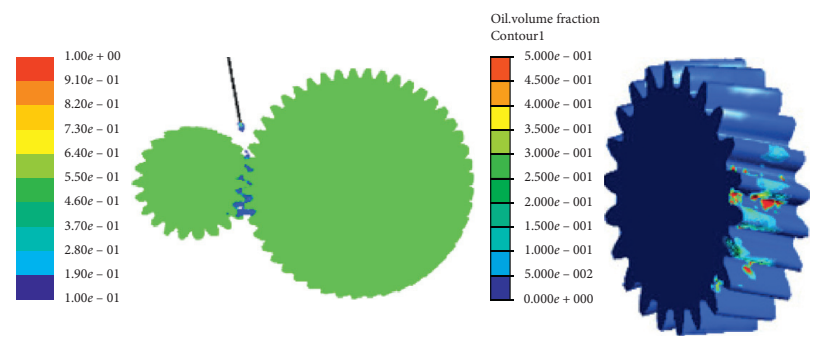

(e)

FIGURE 6: Flow field distribution of the meshing side under different injection angles: (a) $0^{\circ}$; (b) $2.5^{\circ}$; (c) $5^{\circ}$; (d) $7.5^{\circ}$; (e) $10^{\circ}$. 


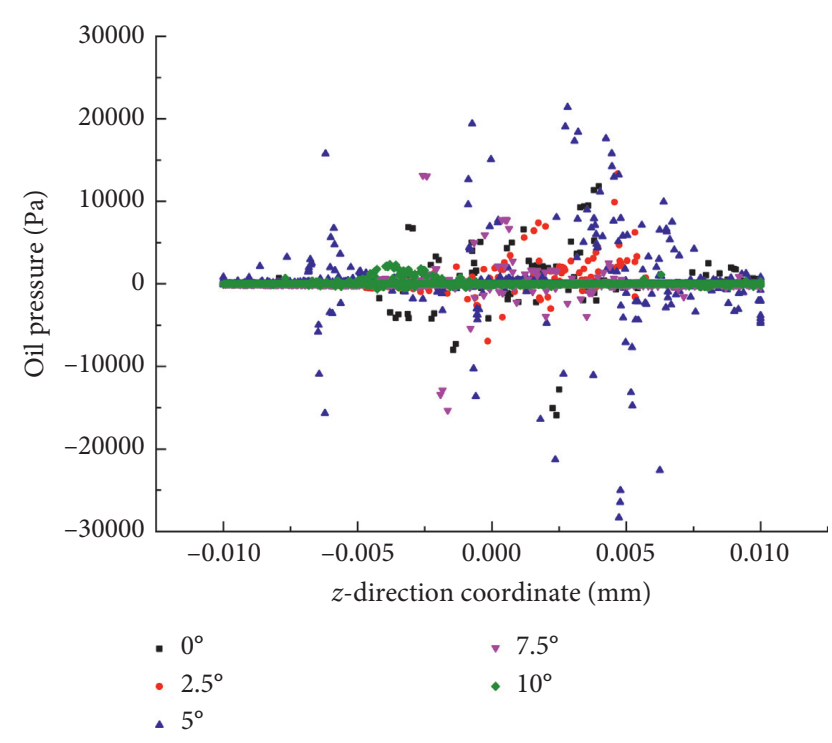

FIGURE 7: Oil pressure distribution in the tooth width direction.

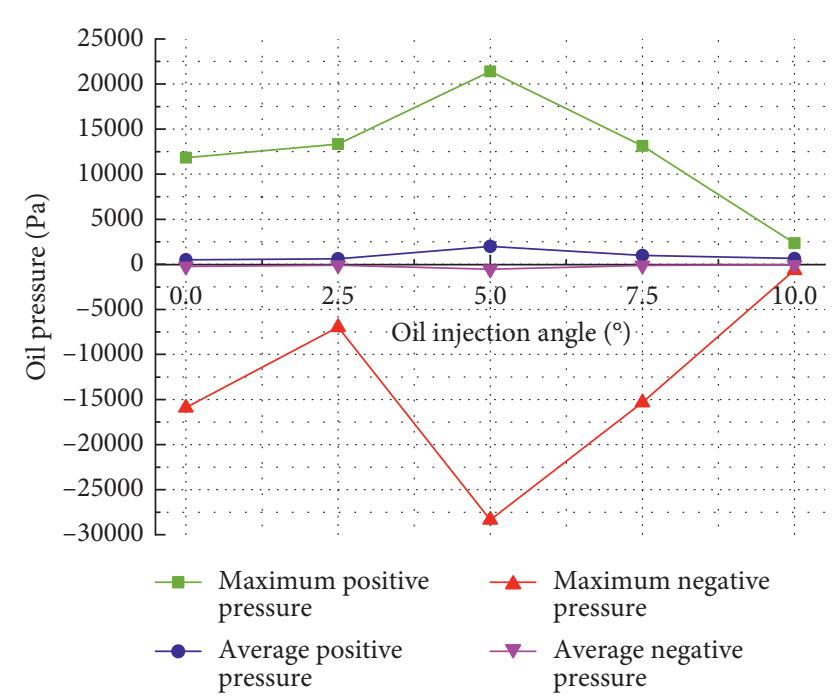

FIGURE 8: Oil pressure line diagram at different injection angles.

maximum average value of the oil pressure in the meshing zone occur when the oil jet velocity is $30 \mathrm{~m} / \mathrm{s}$. Therefore, the jet lubrication performance of the helical gear is the best when the oil jet velocity is $30 \mathrm{~m} / \mathrm{s}$.

\subsection{Influence of Different Gear Ratios on Lubrication Effect.} In order to study the influence of different transmission ratios on the lubrication effect. Since the lubrication performance of the driving gear is mainly concerned, the tooth number of the driving gear is fixed as 22 , and we only change the tooth number of the driven gear to alter the gear ratio; the tooth number of the driven gear is selected as $27,37,47$, and 57 , respectively. The injection angle is $5^{\circ}$, the driving gear speed is $3000 \mathrm{r} / \mathrm{min}$, and the oil jet velocity is set to $30 \mathrm{~m} / \mathrm{s}$. The simulation results are shown in Figure 12 .

It can be seen from Figure 12 that as the gear ratio increases, the oil spot area of the tooth surface gradually decreases, while the volume fraction of the lubricating oil shows a trend of increasing at first and then decreasing. In order to further determine the optimal parameter, a scatter plot of the oil pressure distribution (shown in Figure 13) and a pressure against different gear ratios (shown in Figure 14) on a plane $y=0.1 \mathrm{~mm}$ near the meshing zone are illustrated. As seen in Figure 13, the peak value of oil pressure and the density of its distribution along the tooth width are the largest when the transmission ratio is $37 / 22$. It can be seen from Figure 14 that the maximum value and the maximum average value of the oil pressure in the meshing zone occur when the gear ratio is $37 / 22$. This is because as the gear ratio increases, the phenomenon that the driven gear blocks the lubricant oil flow to the driving gear is more obvious. Therefore, the oil jet lubrication performance of the helical gears is the best when the gear ratio is $37 / 22$.

\section{Heat-Flow Coupling Temperature Field Simulation}

4.1. Theoretical Calculation. Given the complicated process of the heat generation, this paper mainly considered the generation of heat by friction. The friction heat during the meshing is mostly generated by sliding friction, while the rolling friction between two gears and the friction caused by gear deformation can be ignored.

According to Long et al. [25], the input heat of the gear is approximately the average value of the heat flow generated in one rotation period and can be expressed as

$$
q=\frac{b \beta Q \omega}{2 \pi \nu}=\sqrt{\frac{8 R p_{c a}}{\pi E^{\prime}}} \cdot \frac{\beta Q \omega}{2 \pi \nu},
$$

where $b$ represents the contact half-width at the meshing point and can be calculated using the Hertz formula; $\beta$ represents the distribution factor for the friction heat flux; $\omega$ and $v$ represent the angular velocity and the tangential velocity at meshing point, respectively; $Q$ represents the average friction heat; $p_{c a}$ represents the calculated load on the gear; $R$ represents the equivalent radius of curvature; and $E^{\prime}$ represents the gear equivalent elasticity modulus.

The friction heat generation of gear is not only related to Hertz contact pressure, relative sliding speed of gear teeth, and friction coefficient of gear teeth but also related to material and heat distribution coefficient of gear. The calculation formula of the instantaneous friction heat flux of the pinion and gear is as follows:

$$
\left\{\begin{array}{l}
q_{1}=\eta \beta \mu P_{a} v_{0} \times 10^{9} \\
q_{2}=\eta(1-\beta) \mu P_{a} v_{0} \times 10^{9}
\end{array}\right.
$$

where $\eta$ represents the thermal energy conversion coefficient (usually $0.90 \sim 0.95$ ) and $\beta$ represents the heat flux density distribution coefficient, and

$$
\beta=\frac{\sqrt{\lambda_{1} \rho_{1} c_{1} v_{1}}}{\sqrt{\lambda_{1} \rho_{1} c_{1} v_{1}}+\sqrt{\lambda_{2} \rho_{2} c_{2} v_{2}}},
$$

where $\lambda_{1}$ and $\lambda_{2}$ represent the thermal conductivity of the material of the pinion and gear, $\mathrm{W} /(\mathrm{m} \cdot \mathrm{K}) ; \rho_{1}$ and $\rho_{2}$ 
Oil.volume fraction

Contour 1

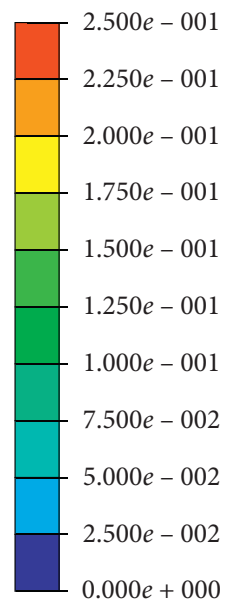

Oil.volume fraction Contour 1
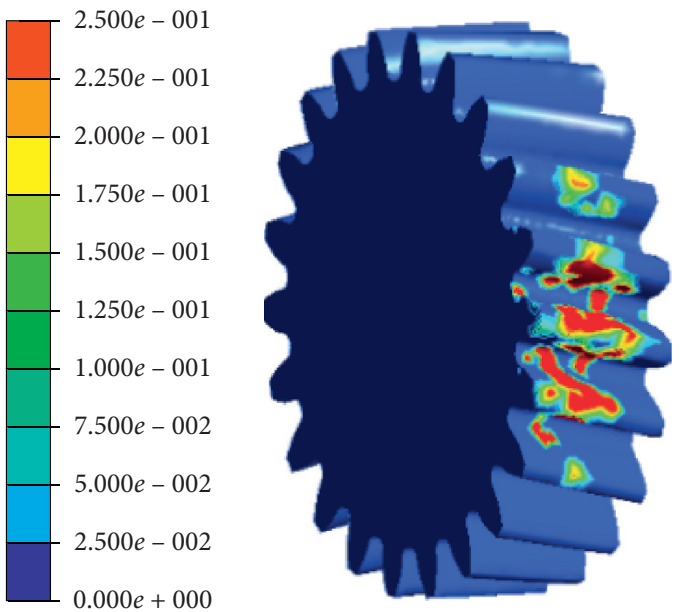

(c)

Oil.volume fraction Contour 1
Oil.volume fraction Contour 1
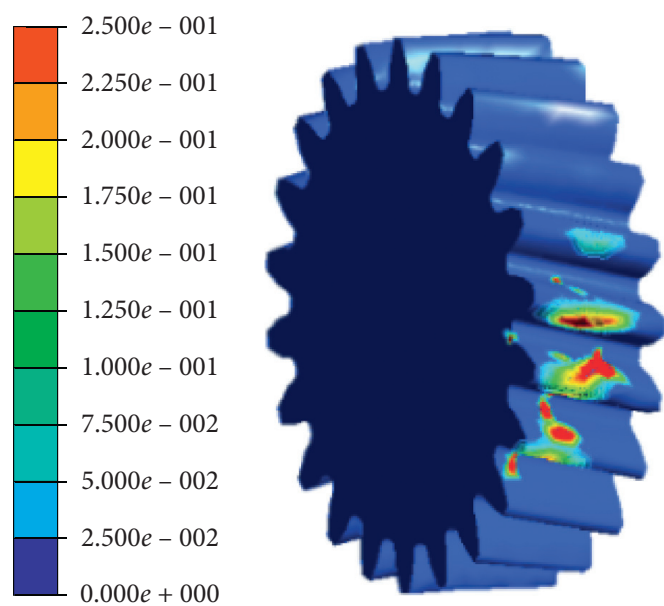

(b)

Oil.volume fraction Contour 1
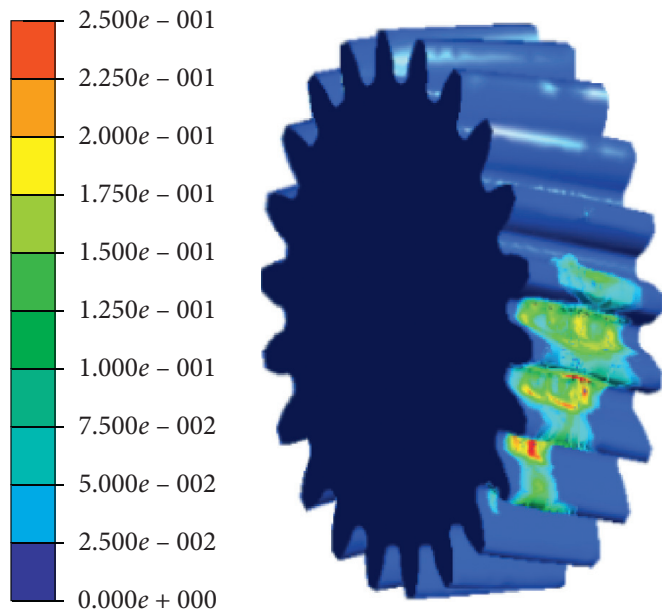

(d)
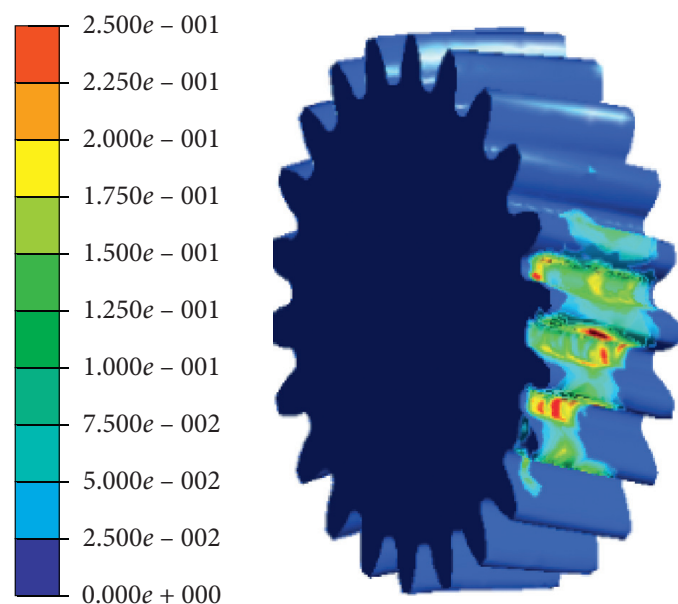

(e)

FIGURE 9: Oil distribution on driving gear tooth surface: (a) $20 \mathrm{~m} / \mathrm{s}$; (b) $25 \mathrm{~m} / \mathrm{s}$; (c) $30 \mathrm{~m} / \mathrm{s}$; (d) $35 \mathrm{~m} / \mathrm{s}$; (e) $40 \mathrm{~m} / \mathrm{s}$. 


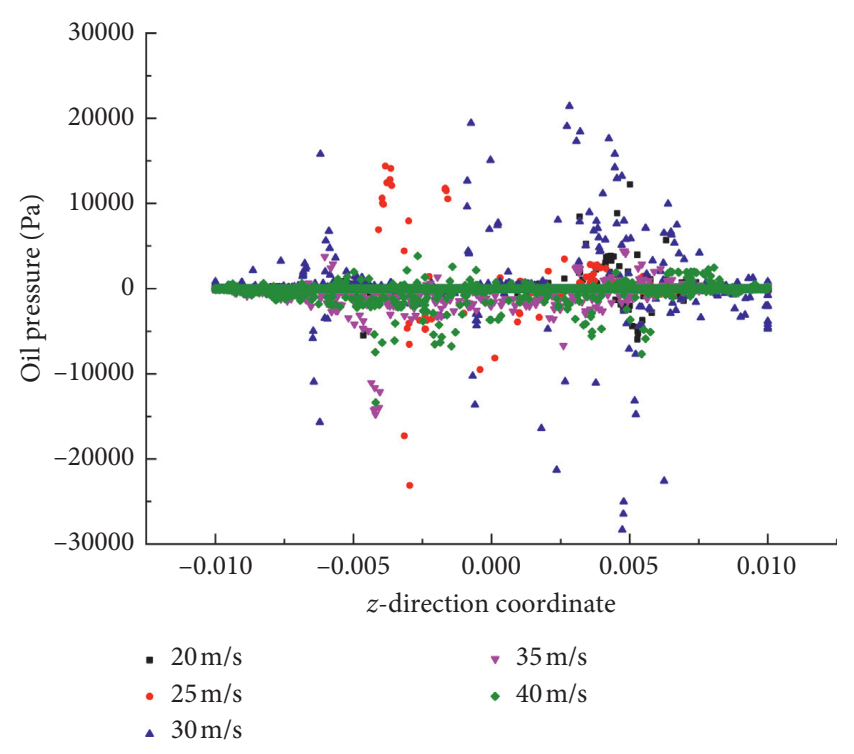

Figure 10: Oil pressure distribution along the tooth width direction.

represent the density of the material of the pinion and gear, $\mathrm{kg} / \mathrm{m}^{3}$; and $c_{1}$ and $c_{2}$ represent the specific heat capacity of the material of the pinion and gear, $\mathrm{J} /(\mathrm{kg} \cdot \mathrm{K})$.

In the numerical analysis of the transient temperature field of the helical gear, the periodic thermal load is applied to each gear tooth, and the thermal load is guaranteed to be applied to each gear tooth once when the gear rotates for one cycle. In this paper, the average friction heat flux at the contact point of the driving and driven gear tooth surface in a rotation cycle is taken as the input heat load, and the formula is as follows:

$$
\left\{\begin{array}{l}
q_{1 a v c}=\frac{a n_{1}}{30000 v_{1}} q_{1} \\
q_{2 a v c}=\frac{a n_{2}}{30000 v_{2}} q_{2}
\end{array}\right.
$$

where the unit of $q_{1 a v c}$ and $q_{2 a v c}$ is $\mathrm{W} / \mathrm{m}^{2}$.

4.2. Basic Settings. General settings are consistent with the flow field except for the added coupling module. The energy equation is turned on, and the temperature field boundary is set via system coupling to couple with the heat generation of the transient thermal module to achieve convective heat transfer of the gear.

The helical gears' structure parameters and the rotation speed of the driving gear remain the same, and only the temperature distribution on the tooth surface of the helical gear under different injection speeds is mainly discussed here. Transient temperature is the superposition of steadystate temperature and instantaneous temperature rise. In this paper, the steady-state temperature field is not studied. It is assumed that the steady-state temperature of the gear is fixed at $50^{\circ} \mathrm{C}$, which is set as the initial temperature of the gear. The time step is $1 . e-005 \mathrm{~s}$, and the operation time is

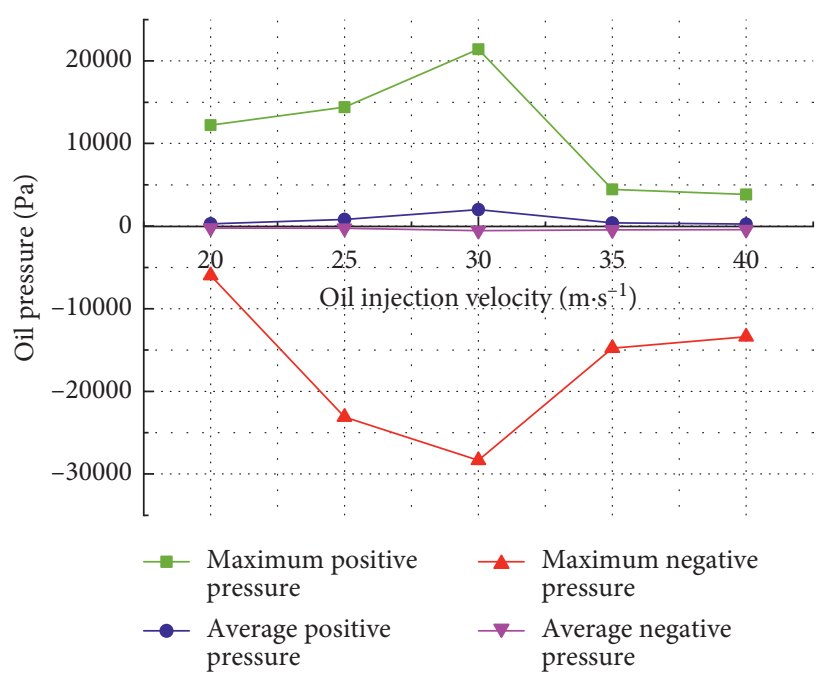

FIGURE 11: Oil pressure line diagram against different injection angles.

$0.02 \mathrm{~s}$. The tooth surface and the end surface of the driving gear are defined as a heat flow coupling surface, and the setting of the driven gear is also coupled with the flow field. Heat source loading: during the meshing process, the heat flux density changes with time and position. Therefore, the gear meshing surface is loaded with a periodic moving heat source. In this paper, the instantaneous friction heat generation process is appropriately simplified, and the two gear teeth are gradually loaded as a load step. Taking the driving gear as an example, the driving gear rotates for one week and loads 11 load steps in turn. The duration of the load step is $0.00182 \mathrm{~s}$, and the heat flux density of all other load steps is removed each time a load step is loaded. Figure 15 shows the loading process of the instantaneous friction heat flux at the first load step on the driving gear.

4.3. Result Analysis. The transient temperature field of the helical gear based on the heat flow coupling is obtained. Figure 16 shows the transient temperature nephogram and temperature isogram chart of the surface of the driving gear when the gear rotates for $0.02 \mathrm{~s}$ under dry running conditions.

As seen in Figure 16, in the case of dry running, the instantaneous maximum temperature is near the pitch circle of the surface of the driving wheel tooth, which is $82.35^{\circ} \mathrm{C}$. Along with the tooth width direction, though the frictional heat generation in the center of the gear mesh is larger and the heat dissipation conditions at both ends of the gear teeth are good, the instantaneous temperature at both ends is lower than that at the center portion.

Figure 17 shows the instantaneous temperature distribution of the tooth surface of the driving gear against different oil jet velocities. Figure 17(L) shows the instantaneous temperature distribution of the gear teeth in the global scope. In order to compare and analyze the influence of different velocity on the instantaneous temperature distribution of the tooth surface, the uniform temperature range is $50^{\circ} \mathrm{C}-58^{\circ} \mathrm{C}$, as shown in Figure $17(\mathrm{R})$. 
Oil.volume fraction

Contour 1

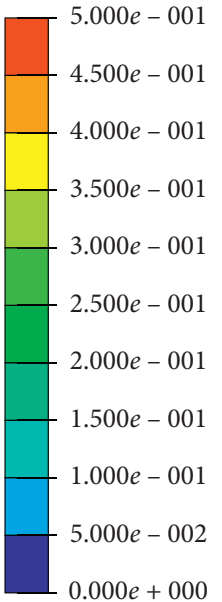

Oil.volume fraction Contour 1

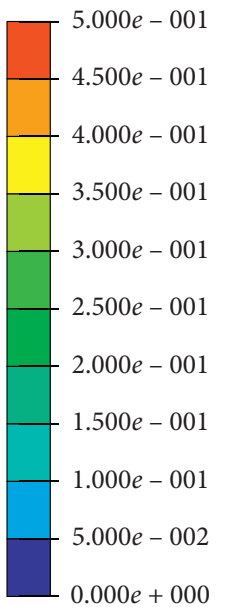

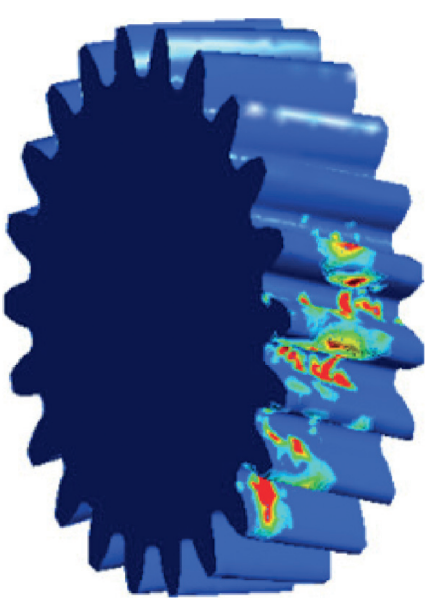

(a)

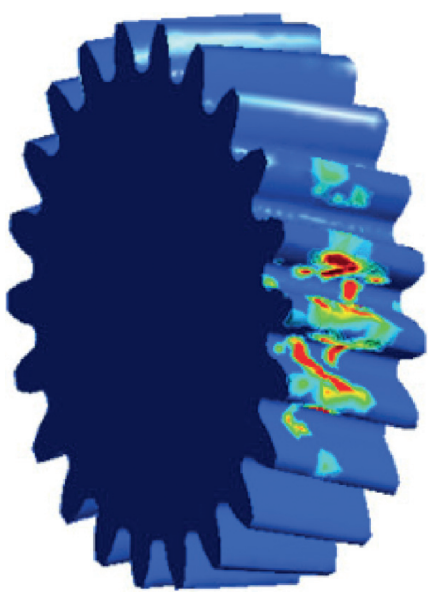

(c)
Oil.volume fraction

Contour 1

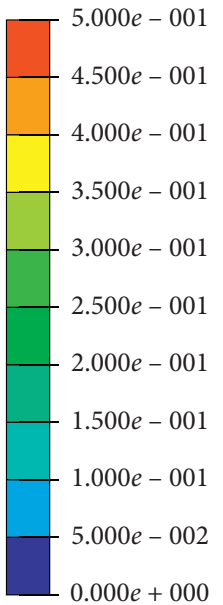

Oil.volume fraction Contour 1

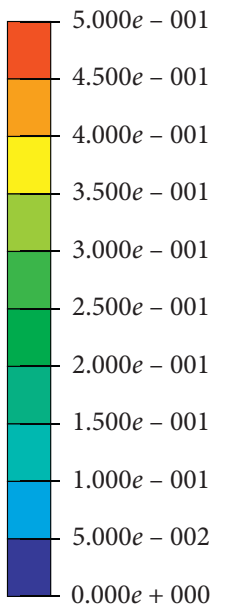

$0.000 e+000$

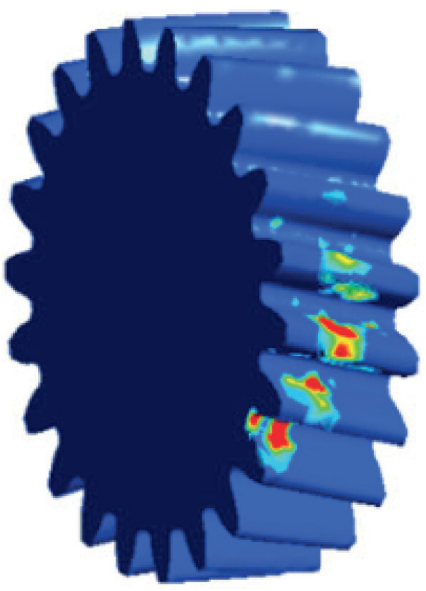

(d)

FIGURE 12: Oil distribution on tooth surface of the driving gear versus different tooth number of the driven gear: (a) 27; (b) 37 ; (c) 47 ; (d) 57.

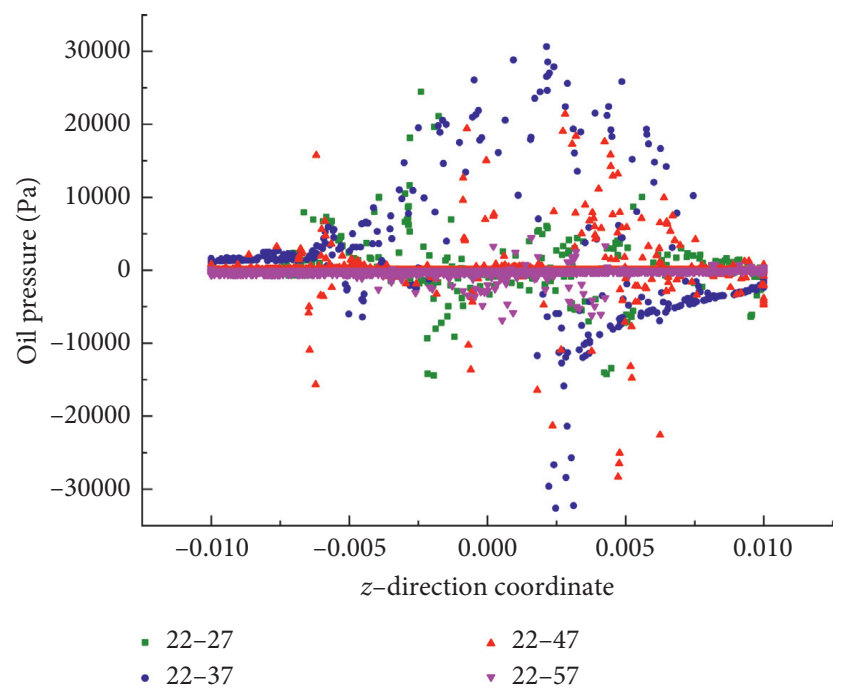

Figure 13: Oil pressure distribution along the tooth width direction.

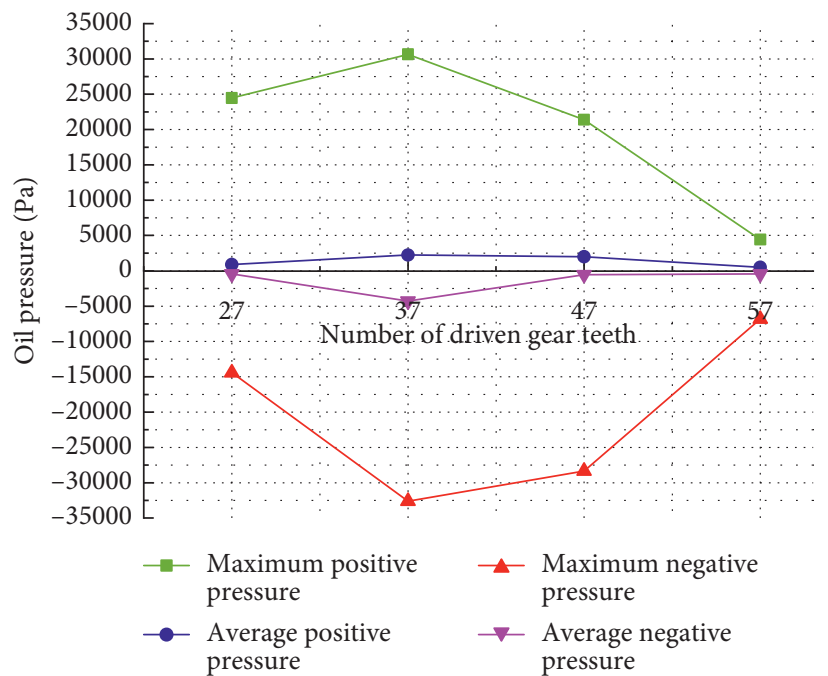

FIgURE 14: Oil pressure against different injection angles. 


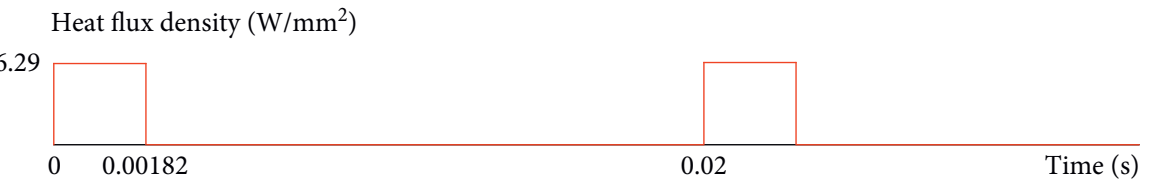

FIgURE 15: The loading process of the first load step of the driving gear.

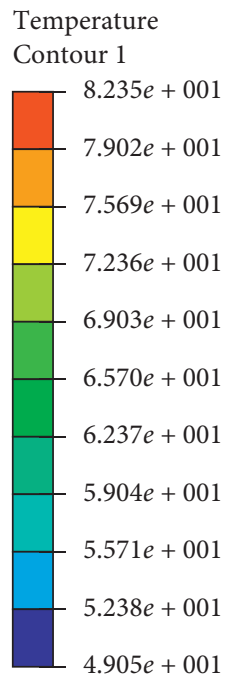

$\left({ }^{\circ} \mathrm{C}\right)$

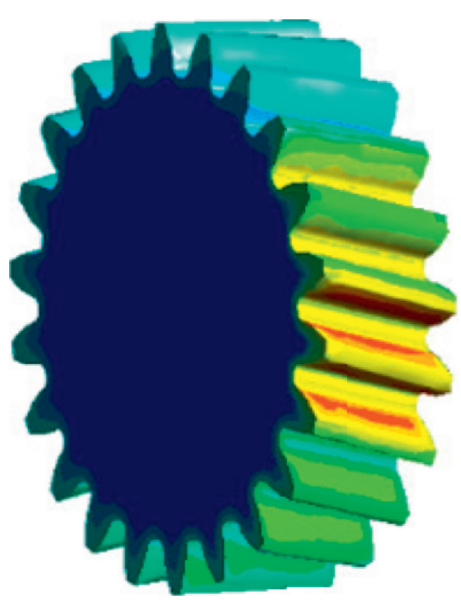

(a)

\section{Temperature \\ Contour 1}

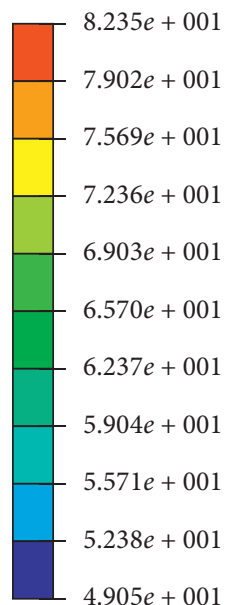

$\left({ }^{\circ} \mathrm{C}\right)$

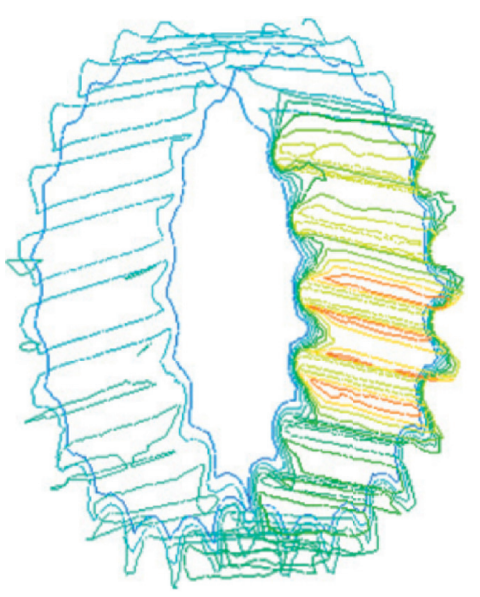

(b)

FIGURE 16: The transient temperature nephogram and temperature isogram chart.
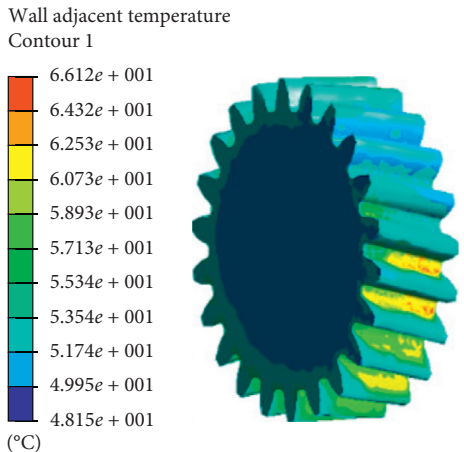

(L)

(a)

Wall adjacent temperature Contour 1
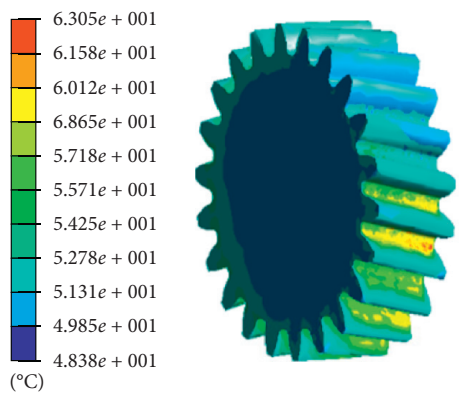

(L)

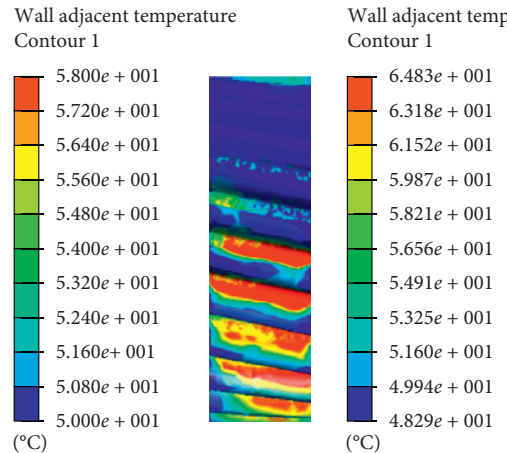

(R)

Wall adjacent temperature Contour 1
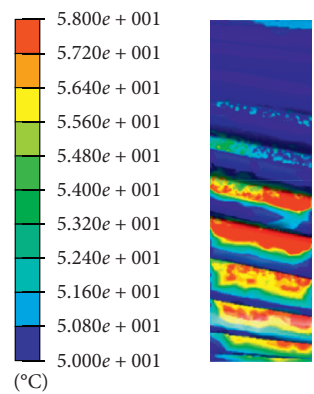

(R)

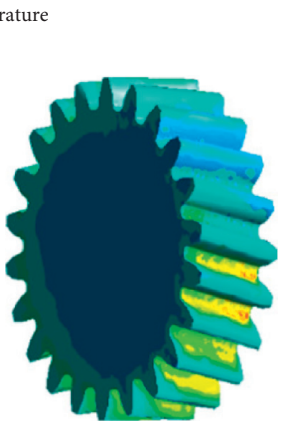

(L)

Wall adjacent temperature Contour 1

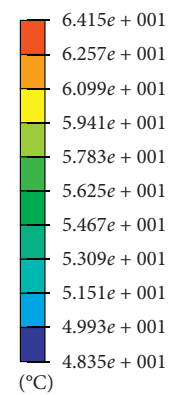

( $\left.{ }^{\circ} \mathrm{C}\right)$

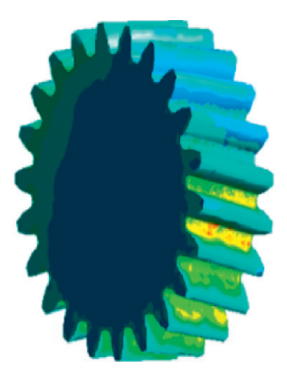

(L)
Wall adjacent temperature Contour 1

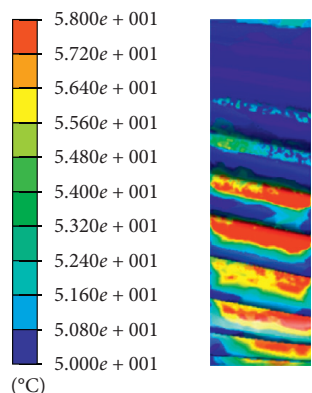

(R)

Wall adjacent temperature Contour 1

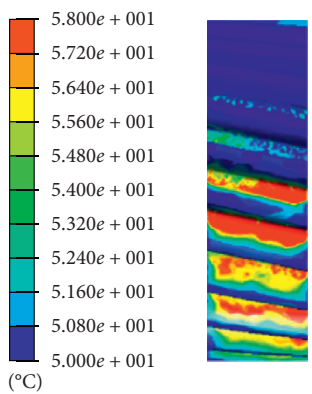

(R)

(c)

FIgURE 17: Continued.

(d) 


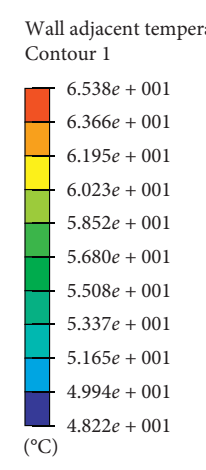

$(\mathrm{L})$

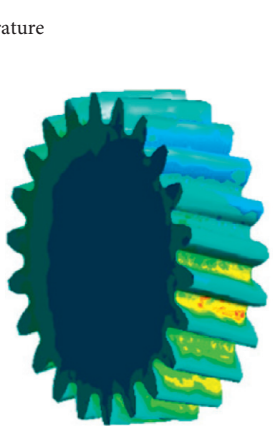

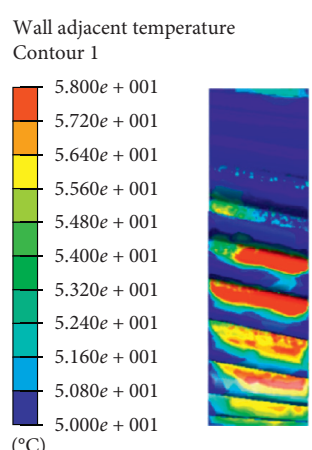

(R)

(e)

Figure 17: Transient temperature distribution against different oil jet velocities: (a) $20 \mathrm{~m} / \mathrm{s}$; (b) $25 \mathrm{~m} / \mathrm{s}$; (c) $30 \mathrm{~m} / \mathrm{s}$; (d) $35 \mathrm{~m} / \mathrm{s}$; (e) $40 \mathrm{~m} / \mathrm{s}$.

TABLe 4: Simulation results at different oil jet velocities.

\begin{tabular}{|c|c|c|c|c|c|c|}
\hline \multirow[b]{2}{*}{ Number } & \multirow[b]{2}{*}{$\begin{array}{l}\text { Oil jet velocity } \\
\qquad(\mathrm{m} / \mathrm{s})\end{array}$} & \multirow[b]{2}{*}{$\begin{array}{c}\text { The initial } \\
\text { temperature }\left({ }^{\circ} \mathrm{C}\right)\end{array}$} & \multicolumn{2}{|c|}{ No lubrication } & \multicolumn{2}{|c|}{ Oil jet lubrication } \\
\hline & & & $\begin{array}{c}\text { Transient } \\
\text { temperature }\left({ }^{\circ} \mathrm{C}\right)\end{array}$ & $\begin{array}{c}\text { Instantaneous } \\
\text { temperature rise }\left({ }^{\circ} \mathrm{C}\right)\end{array}$ & $\begin{array}{c}\text { Transient } \\
\text { temperature }\left({ }^{\circ} \mathrm{C}\right)\end{array}$ & $\begin{array}{c}\text { Instantaneous } \\
\text { temperature rise }\left({ }^{\circ} \mathrm{C}\right)\end{array}$ \\
\hline 1 & 20 & 50 & 82.35 & 32.35 & 66.12 & 16.12 \\
\hline 2 & 25 & 50 & 82.35 & 32.35 & 64.83 & 14.83 \\
\hline 3 & 30 & 50 & 82.35 & 32.35 & 63.05 & 13.05 \\
\hline 4 & 35 & 50 & 82.35 & 32.35 & 64.15 & 14.15 \\
\hline 5 & 40 & 50 & 82.35 & 32.35 & 65.38 & 15.38 \\
\hline
\end{tabular}

Comparing Figures 17 with 16, it can be seen that when the gear rotates for the same time, the tooth surface temperature is lower when the gear is oil jet lubricated, indicating that the lubricating oil and the tooth surface are convectively exchanged. The lubricating oil is sprayed from the meshing side to the gear, and the tooth surface temperature near the impingement point is the lowest. The lubricating oil reaches the meshing zone as the gear rotates, and convective heat exchange happens on the tooth surface and takes away most of the heat, realizing the effect of cooling and lubrication.

It can be seen from Figure 17(R) that the difference of the instantaneous temperature distribution on the tooth surface against different oil jet velocities is obvious. With the increase of the oil jet velocity, the area of the high temperature on the tooth surface (red area in the figure) decreases at first and then increases. It shows that increasing the oil jet velocity to a certain extent is beneficial to the oil arriving at the meshing zone to enhance the convective heat transfer yield, improving the lubrication effect of the gear. However, when the oil jet velocity is too large, the splash phenomenon of the lubricating oil near the impingement point becomes more and more serious, and the lubricating oil entering the meshing zone is reduced. From the above figure, the lubrication effect is best when the oil jet velocity is $30 \mathrm{~m} / \mathrm{s}$.

Table 4 shows the simulation results at different oil jet velocities. The main reason for the scuffing failure of the gear is the maximum instantaneous temperature rise on the tooth surface. Therefore, in the analysis of the temperature distribution on the tooth surface, this paper mainly studies the maximum instantaneous temperature rise on the tooth surface. In order to more clearly compare the influence of different oil jet velocities on the instantaneous temperature rise, the instantaneous temperature rise diagram of the tooth surface of each model is drawn, as shown in Figure 18.

Since the frictional heat generation is related to the parameters and working conditions of the gear pair, the instantaneous friction temperature rise calculated according to the frictional heat generation formula is equal, both being $32.35^{\circ} \mathrm{C}$. It can be seen from Figure 18 that the gear rotates for the same time, and as the oil jet velocity increases, the instantaneous temperature rise on the tooth surface gradually decreases and then gradually increases. If the oil jet velocity is too slow, sufficient oil does not reach the meshing zone. While the oil jet velocity is too high, the oil splash phenomenon near the impingement point is serious. It can be concluded that the instantaneous temperature rise of the tooth surface is the lowest when the injection speed is $30 \mathrm{~m} / \mathrm{s}$, and the lubrication effect is the best.

\section{Experiments}

5.1. Experimental System. Figure 19 shows the view of the test rig.

5.2. Result Analysis. The purpose of experiments is to investigate the variation trend of the tooth surface temperature under the influence of oil jet velocity and gear ratio. Taking into account the limitations of the operating conditions of the test bench and the safety of the operation, the speed of the driving gear in the experiment is set 


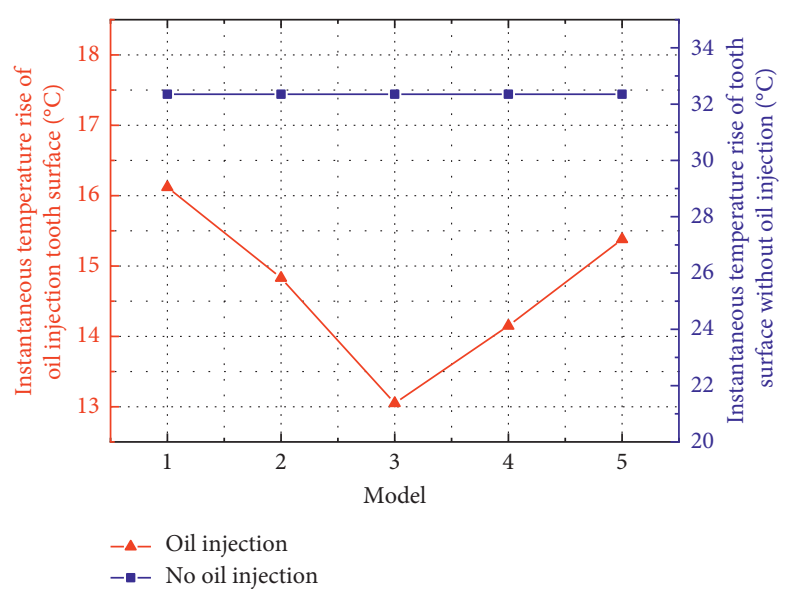

FiguRE 18: Instantaneous temperature rise on the tooth surface.
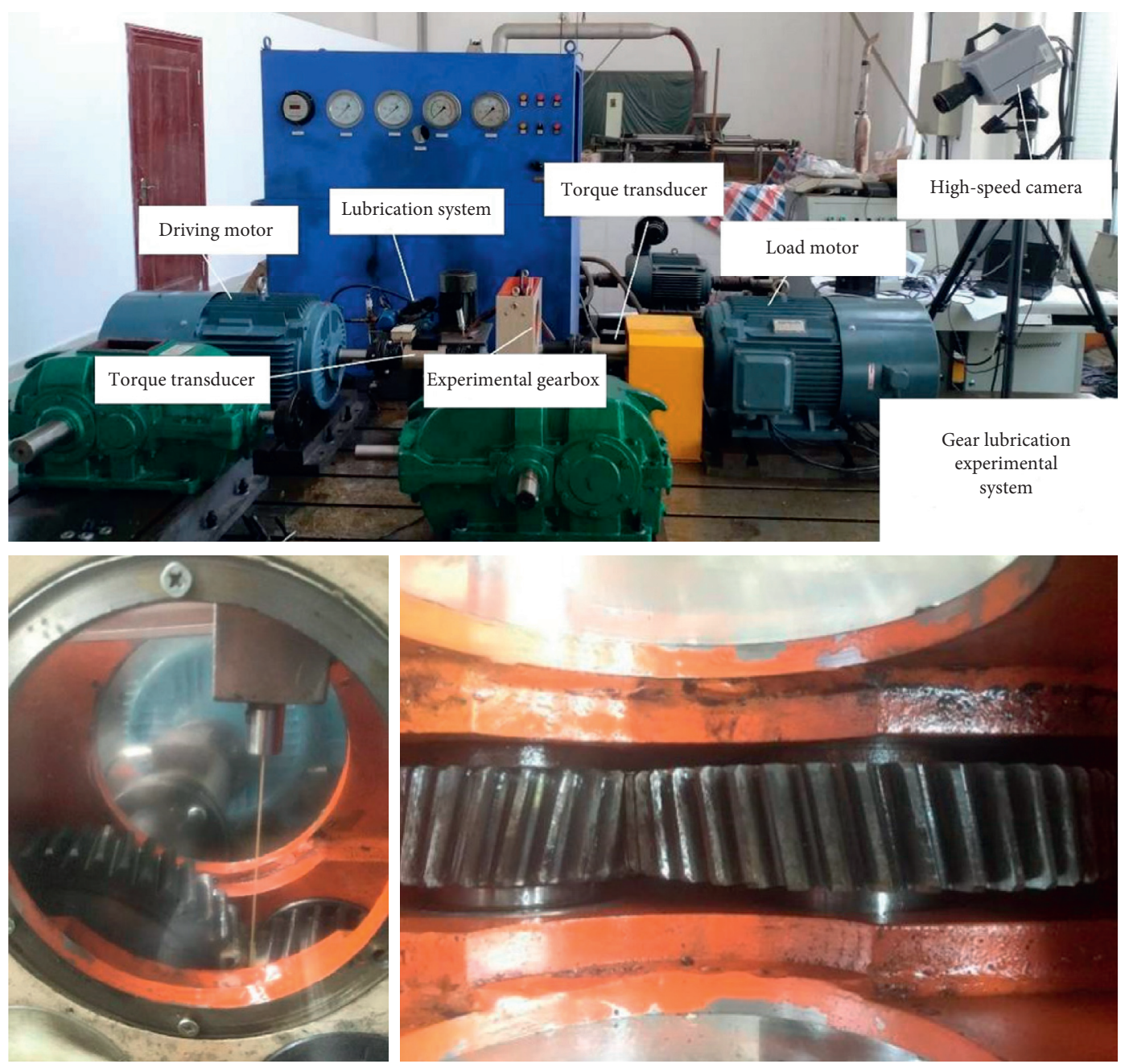

Figure 19: View of the test rig.

to $1500 \mathrm{r} / \mathrm{min}$, the torque is $150 \mathrm{~N} \cdot \mathrm{m}$, and the injection angle is $5^{\circ}$. In order to keep the ratio of oil jet velocity to gear speed consistent with the simulation, the oil jet velocity and corresponding flow rate of each experiment are as shown in Table 5.
The emissivity and transmittance of the infrared thermal imager are 0.7 and 0.95 . The variation trend of the temperature on the tooth surface with time under different conditions is obtained by the infrared thermal imager timing temperature measurement, as shown in Figure 20. 
TABLE 5: Experimental parameters.

\begin{tabular}{lccccc}
\hline $\begin{array}{l}\text { Model } \\
\text { number }\end{array}$ & Speed of driving gear (r/min) & $\begin{array}{c}\text { Oil jet velocity } \\
(\mathrm{m} / \mathrm{s})\end{array}$ & $\begin{array}{c}\text { Experiment } \\
\text { Speed of driving gear }(\mathrm{r} / \mathrm{min})\end{array}$ & $\begin{array}{c}\text { Oil jet velocity } \\
(\mathrm{m} / \mathrm{s})\end{array}$ & Flow rate $(\mathrm{ml} / \mathrm{min})$ \\
\hline 1 & 3000 & 20 & 1500 & 10 & 301.44 \\
2 & 3000 & 25 & 1500 & 12.5 & 376.80 \\
3 & 3000 & 30 & 1500 & 15 & 452.16 \\
4 & 3000 & 35 & 1500 & 17.5 & 527.52 \\
4 & 3000 & 40 & 1500 & 20 & 602.88 \\
\hline
\end{tabular}

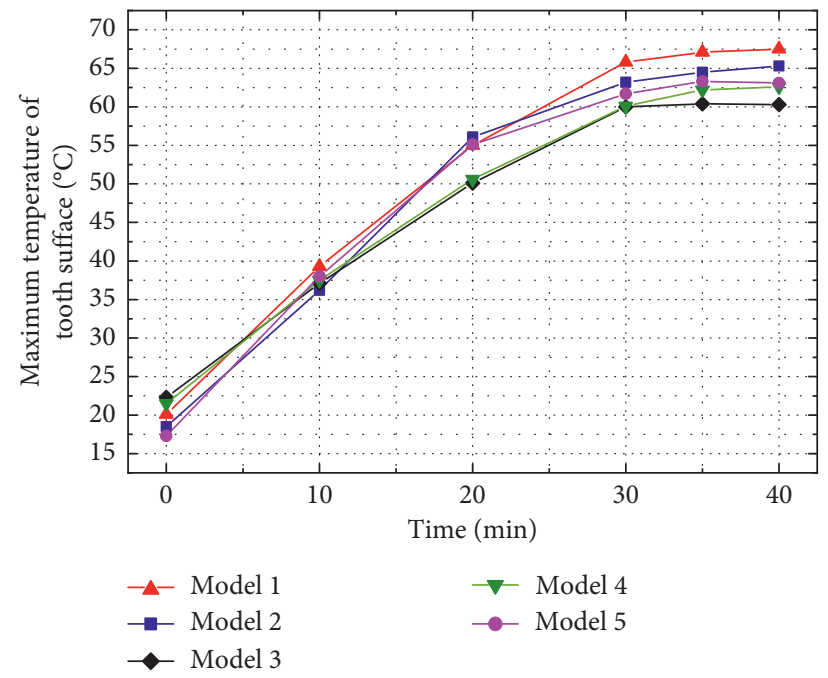

FIgURE 20: The variation trend of tooth surface temperature with time under different models' conditions.

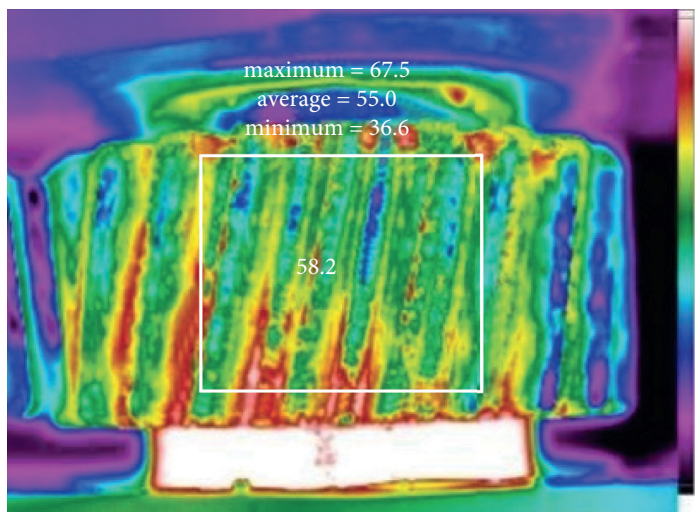

(a)

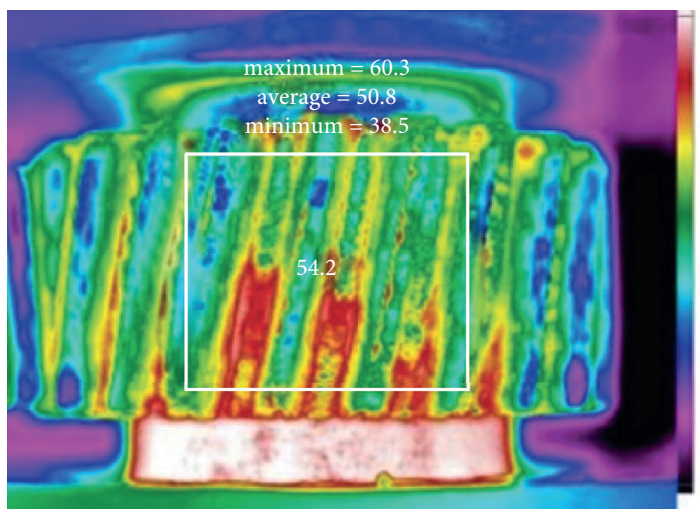

(c)

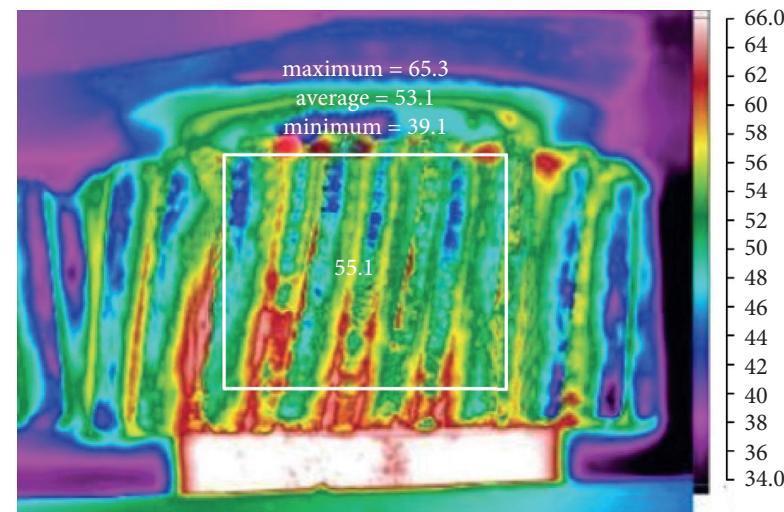

(b)

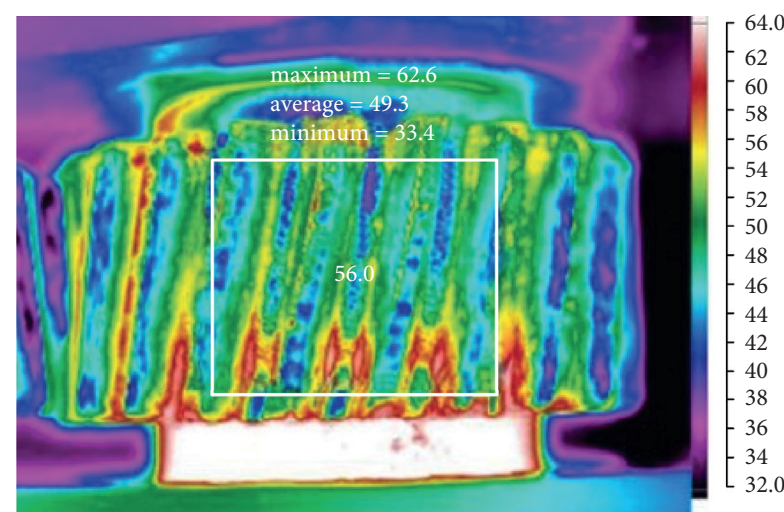

(d)

FIgUre 21: Continued. 


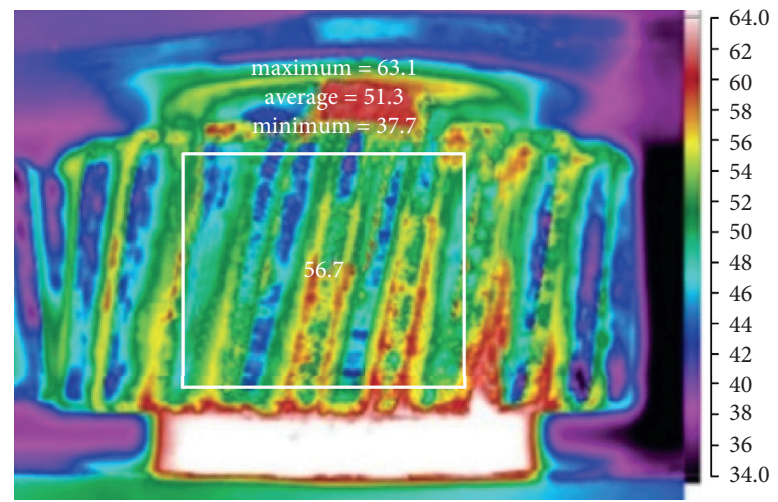

(e)

FIGURE 21: Tooth surface thermal image of the driving gear running for 40 minutes at different injection speeds: (a) Model 1; (b) Model 2; (c) Model 3; (d) Model 4; (e) Model 5.

TABLE 6: Comparison of simulation and experimental data.

\begin{tabular}{lcccc}
\hline Number & 1 & 2 & 3 & 5 \\
\hline The initial temperature $\left({ }^{\circ} \mathrm{C}\right)$ (simulation) & 50.00 & 50.00 & 50.00 & 50.00 \\
The cutoff temperature $\left({ }^{\circ} \mathrm{C}\right.$ ) (simulation) & 66.12 & 64.83 & 63.05 & 64.15 \\
The instantaneous temperature rise $\left({ }^{\circ} \mathrm{C}\right)$ (simulation) & 16.12 & 14.83 & 13.05 & 14.15 \\
The initial temperature $\left({ }^{\circ} \mathrm{C}\right)$ (experiment) & 20.10 & 18.50 & 22.30 & 65.38 \\
The cutoff temperature $\left({ }^{\circ} \mathrm{C}\right.$ ) (experiment) & 67.50 & 65.30 & 60.30 & 15.38 \\
The instantaneous temperature rise $\left({ }^{\circ} \mathrm{C}\right)$ (experiment) & 47.40 & 46.80 & 38.00 & 62.60 \\
\hline
\end{tabular}

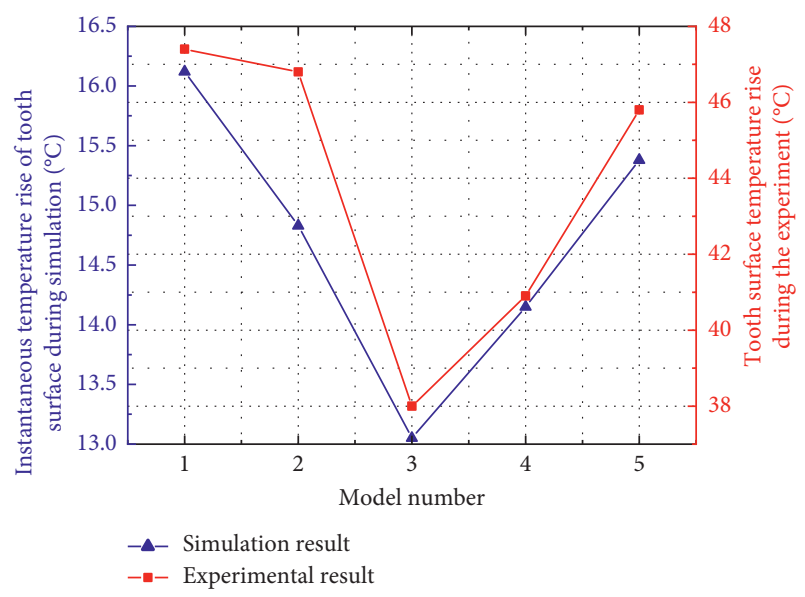

FIGURE 22: Comparison of the temperature rise of the driving gear tooth surface under different conditions.

As can be seen from Figure 20, with the rotation of the gear, the surface temperature of the gear gradually increases and eventually remains constant, reaching an equilibrium state about 30 minutes later. After 20 minutes, the influence of different oil jet velocities on the tooth surface temperature is gradually obvious, and the maximum temperature of the tooth surface of Model 3 is the lowest, indicating that the convection heat transfer between the lubricant and the tooth surface is better and the heat taken away is the most. Via the professional software of Fluke company to process the experimental data, the thermal image of the driving gear tooth surface under different oil jet velocities was acquired when running for 40 minutes, as shown in Figure 21. Obviously, the highest temperature value on the tooth surface of Model 3 (oil jet velocity is $15 \mathrm{~m} / \mathrm{s}$ ) is the lowest.

According to the thermal image of the tooth surface in Figure 21, the temperature distribution along the tooth width direction is not uniform, and the highest temperature zone shifts to one side in the tooth width direction. Because the oil is deflected by compression under the action of axial force, the convective heat transfer is better in the position with high oil pressure and more heat is taken away, which match well with the simulation results.

To analyze the influence of the ratio of oil jet velocity to gear speed on tooth surface temperature rise, the experimental data are compared with the simulation results, which are shown in Table 6 . The curve of temperature rise of tooth surface with oil jet velocity is shown in Figure 22.

It can be seen from Figure 22 that the experimental results are in good agreement with the simulation results. The temperature rise of the driving wheel tooth surface decreases at first and then increases with the increase of oil jet velocity. It proves that the simulation method based on thermal-fluid coupling is feasible to predict the temperature field of the helical gear pair under oil jet lubrication. However, there is a major error in Model 2, which is mainly due to the following reasons: the simulations are too idealistic and the residual oil on the tooth surface of gear teeth causing local high temperature could influence the measurements.

\section{Conclusions}

(1) The mathematical model of impingement depth for the helical gear under oil jet lubrication is established, which provides useful guidance for the layout 
of the nozzle. The flow field simulations are used to analyze the influence of different injection angles, oil jet velocities, and gear ratios on lubrication performance. The results show that the lubrication effect achieves the best when the nozzle is biased toward the driving gear by $5^{\circ}$, and increasing the oil jet velocity within certain range is beneficial to the lubrication oil entering the gear meshing area, thereby increasing the oil pressure in the meshing area and improving the lubrication performance of helical gears. The lubrication effect of helical gears is the best when the oil jet velocity is $30 \mathrm{~m} / \mathrm{s}$. With the increase of the tooth number of driven gear (i.e., gear ratio), the shielding effect of the driven gear on the oil of the driving gear is more obvious. When the oil injection angle is selected as $5^{\circ}$ for simulation, it is concluded that the helical gears have the best lubricating effect when the gear ratio is $37 / 22$.

(2) The instantaneous frictional heat flux density on the tooth surface of the driving wheel was calculated and loaded as a periodically moving heat source. The coupled thermal-fluid simulation model of helical gear was established, and the instantaneous temperature distribution on the tooth surface at different injection speeds was simulated. The results show that the instantaneous temperature of the tooth surface under oil jet lubrication is obviously lower than that without oil jet lubrication; with the increase of oil injection speed, the instantaneous temperature of the tooth surface at first increases and then decreases, and the instantaneous temperature on the tooth surface is the lowest as the oil injection speed is $30 \mathrm{~m} / \mathrm{s}$.

(3) The temperature distribution on the gear surface at different oil jet velocities was captured through experiments, and the results were compared with the simulation results. The results show that under the same gear parameters, the best simulation and experimental lubrication results are obtained by Model 3. The simulation results are in good agreement with the experimental results, which proves that the simulation method based on thermal-fluid coupling is accurate and credible for predicting the temperature field of the helical gear pair under oil jet lubrication.

\section{Data Availability}

The data used to support the findings of this study are included within the supplementary information file.

\section{Conflicts of Interest}

The authors declare no conflicts of interest.

\section{Acknowledgments}

The authors would like to thank the National Defense Preliminary Research Project of China (grant no. KY-442018-0219) for the support.

\section{Supplementary Materials}

Figure1-1: the interface of the calculation platform for the impingement depth of oil injection lubrication of helical gears. Figure 2-1: profiles file. Figure 2-2: the velocity flow diagram under different injection angles: (a) $0^{\circ}$; (b) $2.5^{\circ}$; (c) $5^{\circ}$; (d) $7.5^{\circ}$; (e) $10^{\circ}$. Figure 3-1: the test rig. Figure3-2: Ti32 infrared thermal imager. Table 3-1: main performance parameters of Fluke Ti32 infrared thermal imager. Figure 3-3: control software interface. (Supplementary Materials)

\section{References}

[1] J. W. McCain and E. Alsandor, "Analytical aspects of gear lubrication on the disengaging side," A S L E Trans, vol. 9, no. 2, pp. 202-211, 2008.

[2] L. S. Akin and D. P. Townsend, "Lubricant jet flow phenomena in spur and helical gears with modified center distances and/or addendums-for out-of-mesh conditions," Journal of Mechanisms, Transmissions, and Automation in Design, vol. 107, no. 1, pp. 24-30, 1985.

[3] L. S. Akin and D. P. Townsend, "Into mesh lubrication of spur gears with arbitrary offset oil jet. Part 1: for jet velocity less than or equal to gear velocity," Journal of Mechanisms, Transmissions, and Automation in Design, vol. 105, no. 4, pp. 713-718, 1983.

[4] L. S. Akin and D. P. Townsend, "Into mesh lubrication of spur gears with arbitrary offset oil jet. Part 2: for jet velocities equal to or greater than gear velocity," Journal of Mechanisms, Transmissions, and Automation in Design, vol. 105, no. 4, pp. 719-724, 1983.

[5] L. S. Akin and D. P. Townsend, "Lubricant jet flow phenomena in spur and helical gears with modified addendums - for radially directed individual jets," in Proceeding of the 5th International Power Transmission and Gearing Conference, pp. 367-374, Chicago, IL, USA, 1989.

[6] Y. Wang, G. Song, W. Niu, and Y. Chen, "Optimized design of spray parameters of oil jet lubricated spur gears," Tribology International, vol. 120, pp. 149-158, 2018.

[7] Y. Wang, G. Song, W. Niu, and Y. Chen, "Influence of oil injection methods on the lubrication process of high speed spur gears," Tribology International, vol. 121, pp. 180-189, 2018.

[8] K. Li, G. Chen, and D. Liu, "Study of the influence of lubrication parameters on gear lubrication properties and efficiency," Industrial Lubrication and Tribology, vol. 68, no. 6, pp. 647-657, 2016.

[9] Y. Wang, W. Niu, S. Wei, and G. Song, "Influence of spin flow on lubricating oil jet-Design method of oil spray parameters to high speed spur gears," Tribology International, vol. 92, pp. 290-300, 2015.

[10] Y. Dai, W. Wu, H. B. Zhou, J. Zhang, and F. Y. Ma, "Numerical simulation and optimization of oil jet lubrication for rotorcraft meshing gears," International Journal of Simulation Modelling, vol. 17, no. 2, pp. 318-326, 2018.

[11] Y. Dai, F. Ma, X. Zhu, Q. Su, and X. Hu, "Evaluation and optimization of the oil jet lubrication performance for orthogonal face gear drive: modelling, simulation and experimental validation," Energies, vol. 12, no. 10, p. 1935, 2019.

[12] D. P. Townsend and L. S. Akin, "Study of lubricant jet flow phenomena in spur gears-out of mesh condition," Journal of Mechanical Design, vol. 100, no. 1, pp. 61-68, 1978. 
[13] R. F. Handschuh, "Effect of lubricant jet location on spiral bevel gear operating temperatures," American Society of Mechanical Engineers Design Engineering Division, vol. 43, pp. 275-282, 1992.

[14] J. Moss, A. Kahraman, and C. Wink, "An experimental study of influence of lubrication methods on efficiency and contact fatigue life of spur gears," Journal of Tribology, vol. 14051103 pages, 2018.

[15] D. Massini, T. Fondelli, B. Facchini, L. Tarchi, and F. Leonardi, "High speed visualizations of oil jet lubrication for aero-engine gearboxes," Energy Procedia, vol. 101, pp. 1248-1255, 2016.

[16] F. Tommaso, A. Antonio, B. Facchini, and L. Cipolla, "Volume of fluid (VOF) analysis of oil-jet lubrication for highspeed spur gears using an adaptive meshing approach," Structures and Dynamics, vol. 7A, 2015.

[17] S. Seetharaman and A. Kahraman, "A windage power loss model for spur gear pairs," Tribology Transactions, vol. 53, no. 4, pp. 473-484, 2010.

[18] T. Ouyang, G. Huang, J. Chen, B. Gao, and N. Chen, "Investigation of lubricating and dynamic performances for high-speed spur gear based on tribo-dynamic theory," Tribology International, vol. 136, pp. 421-431, 2019.

[19] L. Gan, K. Xiao, W. Pu, W. Cao, and W. Cao, "A numerical method to investigate the temperature behavior of spiral bevel gears under mixed lubrication condition," Applied Thermal Engineering, vol. 147, pp. 866-875, 2019.

[20] Y. Wang, C. Wu, W. Tang, X.-F. Zhao, Q.-J. Lv, and Y. Lian, "Analysis on isothermal elastohydrodynamic lubrication of orthogonal face gear," Tribology Transactions, vol. 55, no. 6, pp. 863-871, 2012.

[21] M. Y. Liu, P. D. Xu, and C. A. Yan, "Parametric studies of mechanical power loss for helical gear pair using a thermal elastohydrodynamic lubrication model," Journal of Tribology, vol. 141, no. 1, p. 11502, 2019.

[22] D. Dowson, "Elastohydrodynamic and micro-elastohydrodynamic lubrication," Wear, vol. 190, pp. 128-138, 1995.

[23] B. Lars, B. Ronny, B. Dirk, and D. Ludger, "Thermal elastohydrodynamic simulation of involute spur gears incorporating mixed friction," Tribology International, vol. 48, pp. 191-206, 2012.

[24] D. Sujan and V. Andrea, "A fluid structure interaction-EHD model of the lubricating gaps in external gear machines: formulation and validation," Tribology International, vol. 62, pp. 78-90, 2013.

[25] H. Long, A. A. Lord, D. T. Gethin, and B. J. Roylance, "Operating temperatures of oil-lubricated medium-speed gears: numerical models and experimental results," Proceedings of the Institution of Mechanical Engineers, Part G: Journal of Aerospace Engineering, vol. 217, no. 2, pp. 87-106, 2003. 